\title{
Evaluation of Infrasound and Strobe Lights to Elicit Avoidance Behavior in Juvenile Salmon and Char
}

\section{Annual Report}

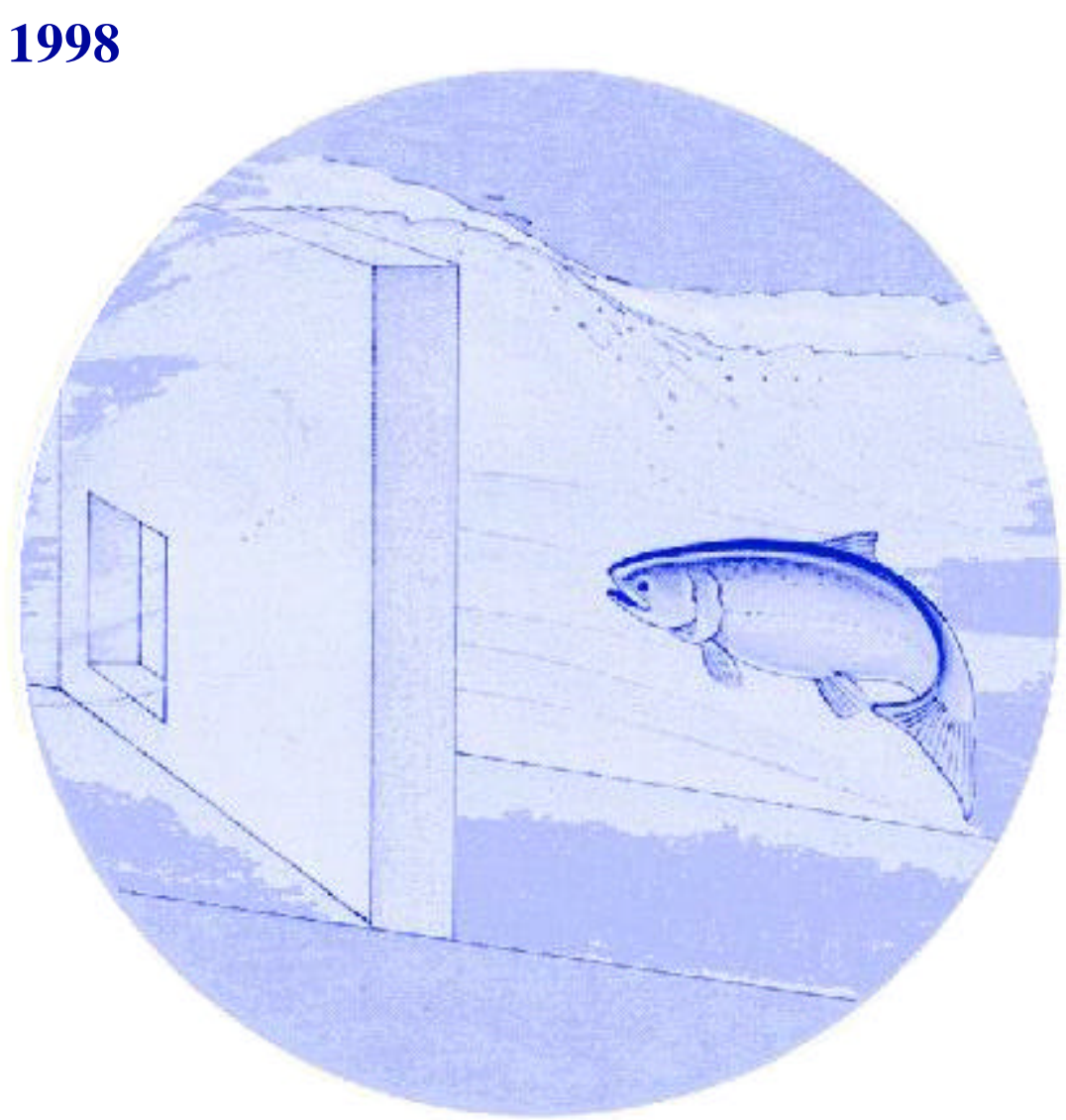

DOE/BP-00029-6

February 1999 
This Document should be cited as follows:

Mueller, Robert, Duane Neitzel, Brett Amidan, "Evaluation of Infrasound and Strobe

Lights to Elicit Avoidance Behavior in Juvenile Salmon and Char", Project No. 1985 -

06200, 39 electronic pages, (BPA Report DOE/BP-00029-6)

\author{
Bonneville Power Administration \\ P.O. Box 3621 \\ Portland, Oregon 97208
}

This report was funded by the Bonneville Power Administration (BPA), U.S. Department of Energy, as part of BPA's program to protect, mitigate, and enhance fish and wildlife affected by the development and operation of hydroelectric facilities on the Columbia River and its tributaries. The views in this report are the author's and do not necessarily represent the views of BPA. 


\title{
Evaluation of Infrasound and Strobe Lights to Elicit Avoidance Behavior in Juvenile Salmon and Char
}

\author{
Prepared by: \\ Robert P. Mueller \\ Duane A. Neitzel \\ Brett G. Amidan \\ Pacific Northwest National Laboratory \\ Richland, WA
}

Prepared for:

\author{
U.S. Department of Energy \\ Bonneville Power Administration \\ Environment, Fish and Wildlife \\ P.O. Box 3621 \\ Portland, OR 97208-3621
}

Project Number 85-062

Task Order 93-AT-39041

Contract Number 93-AI-00029

February 1999 


\section{Preface}

The safe emigration of anadromous juvenile salmonids Oncorhynchus spp. from small tributaries and mainstream rivers to the ocean is vital to the survival of each species. Salmon outmigrating within rivers in the Pacific Northwest face many obstacles in this journey. In irrigated watersheds an important obstacle is diversion dams and the associated screen and pumping systems. The Columbia Basin Fish and Wildlife Program (NPPC 1984, 1987, 1994) provides oversight and funding to ensure safe passage of juvenile salmonids and other resident species past irrigation diversions and screens. The program includes funds to monitor and evaluate the passage facilities. The Pacific Northwest National Laboratory (PNNL) has conducted evaluations at screening facilities for the past 15 years. The goal is to ensure that facilities operate in accordance to design criteria and to make recommendations based on these evaluations to improve facility effectiveness. PNNL's screening evaluations have determined current facilities are effective at protecting juvenile salmonids larger than $40 \mathrm{~mm}$ in length. However, smaller fry may be vulnerable to passing through or around screens and seal gaps (Mueller et al. 1995, Neitzel et al.1990b).

As state and federal agencies change screening criteria to protect smaller fish (e.g., bull trout Salvelinus confluentus fry), physical barriers may not always be effective. Screen mesh small enough to protect fish may be vulnerable to frequent plugging. Gap tolerances on side and bottom seals may be difficult to install and maintain. Physical barrier screens may be enhanced with behavioral barriers that cause fish to avoid a hazard. Behavioral barriers may consist of any condition (e.g., sound, light) that moves a fish away from danger to safety.

The purpose of this study is to evaluate the effectiveness of using an underwater soundgenerator and strobe lights as behavioral barriers for possible use at fish diversion facilities. This

study is a continuation of initial studies conducted in 1996 and 1997 by PNNL to evaluate the effectiveness of using infrasound as a behavior deterrent for salmonid fry (Mueller et al. 1998). This study did not include engineering and economic evaluations needed to produce, deploy or install equipment at existing or planned fish screening facilities. 


\section{Acknowledgments}

The success of this project depended on the involvement and cooperation of many people. The project was managed by Ken Barnhart of the Bonneville Power Administration (BPA). We thank Jeff Condiotty and Frank Knudsen from Simrad Incorporated for their assistance in leasing the infrasound device and Ron Brown from Flash Technology for loaning the strobe lights. We also thank Pacific Northwest National Laboratory (PNNL) staff Fenton Khan, Jeff Marco, and Anita Muzak for their assistance in analysis of the videotapes. Dennis Dauble and Dave Geist reviewed earlier drafts of this report. 


\begin{abstract}
Experimental tests were conducted using hatchery reared and wild juvenile chinook salmon Oncorhynchus tshawytscha, eastern brook trout Salvelinus fontinalis, and rainbow trout $O$. mykiss to determine specific behavior responses to infrasound $(<20 \mathrm{~Hz})$ and flashing strobe lights. Caged fish were acclimated in a static test tank and their behavior was recorded using low light cameras. Species specific behavior was characterized by measuring movements of the fish within the cage as well as observing startle and habituation responses. Wild chinook salmon $(40-45 \mathrm{~mm})$ and hatchery reared chinook salmon (45-50mm) exhibited avoidance responses when initially exposed to a $10 \mathrm{~Hz}$ volume displacement source. Rainbow and eastern brook trout $(25-100 \mathrm{~mm})$ did not respond with avoidance or other behaviors to infrasound. Habituation to the infrasound source was evident for chinook salmon during repeated exposures. Wild and hatchery chinook displayed a higher proportion of movement during the initial exposures to infrasound when the acclimation period in the test tank was $2-3 \mathrm{~h}$ as compared to a 12-15 $\mathrm{h}$ acclimation period. A flashing strobe light produced higher and more consistent movement rates in wild chinook (60\% of the tests); hatchery reared chinook salmon (50\%) and rainbow trout $(80 \%)$. No measurable movement or other responses was observed for eastern brook trout. Little if any habituation was observed during repeated exposures to strobe lights. Results from this study indicate that consistent repeatable responses can be elicited from some fish using high intensity strobe lights under a controlled laboratory testing. The specific behaviors observed in these experiments might be used to predict how fish might react to low frequency sound and strobe lights in a screening facility. Because sub-yearling salmonids and resident species are susceptible from becoming entrained at water diversion structures we conducted tests in conjunction with our evaluation of juvenile fish screening facilities. This is the reason our tests focused on fry life stages.
\end{abstract}




\section{Contents}

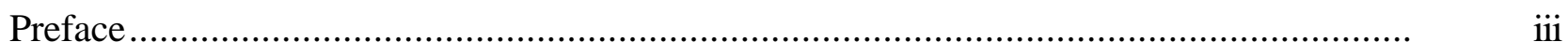

Acknowledgments .............................................................................

Abstract ............................................................................................. vii

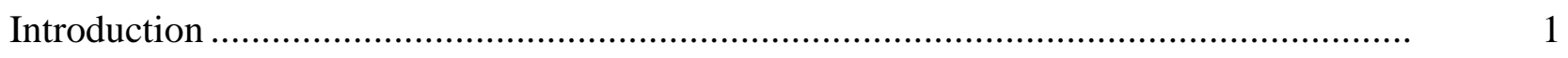

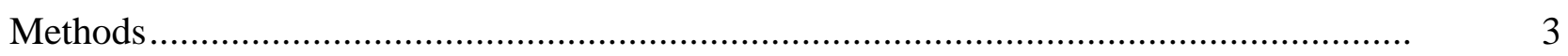

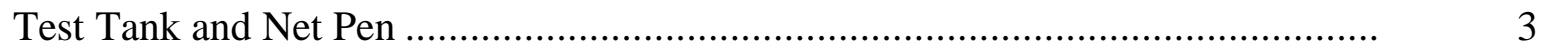

Video Equipment................................................................................... 3

Test Fish.........................................................................................

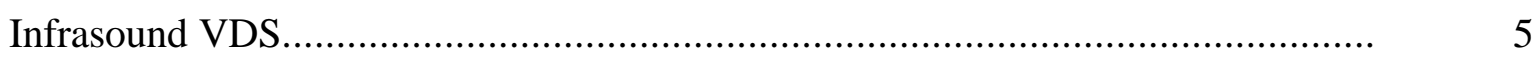

Strobe Lights ....................................................................................

Experimental Procedure ....................................................................... $\quad 6$

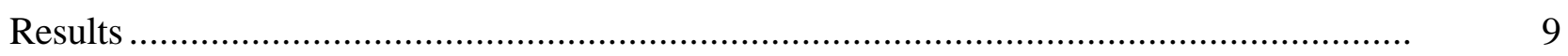

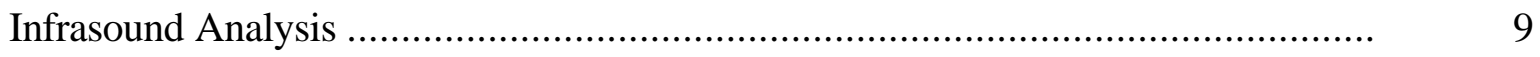

Movement Classification Grades ............................................................ 10

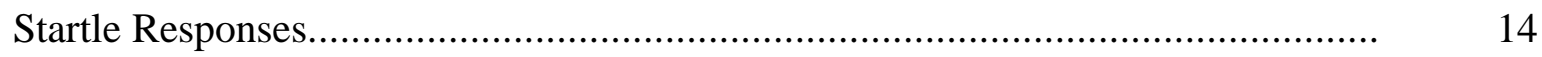

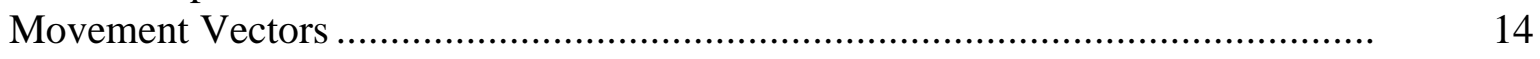

Strobe Light Analysis............................................................................ 19

Movement Classification Grades ................................................................ 19

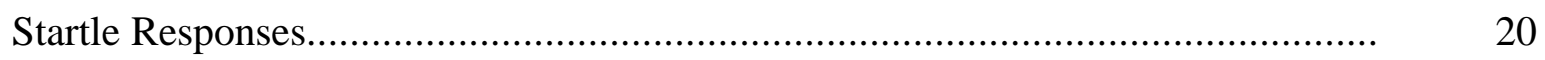

Movement Vectors ................................................................................. 23

Light Intensity Measurements ................................................................ 24

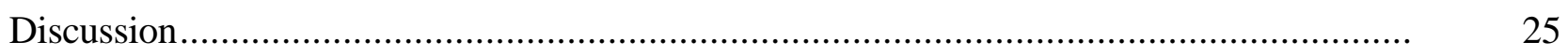

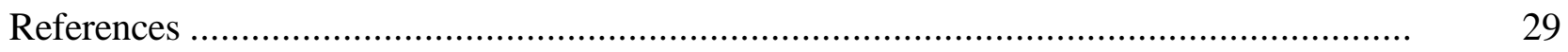




\section{Figures}

$1 \quad$ Birds Eye View of a 3-Dimensional Depiction of the Testing Pen .................................

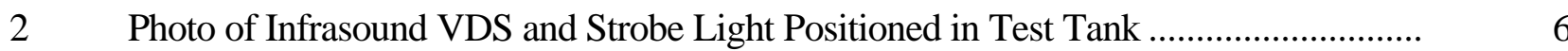

3 The Proportion of Tests That Showed Moderate/Great Movement for Each

Replication During Motor and Sound Testing. .......................................................

4 The Proportion of Tests Which Showed Moderate or Great Movement for Eastern

Brook Trout.....

5 A Proportion of the Tests Where Moderate/Great Movement was Detected During the Sound Testing

6 Each Plot Shows the Proportion of Tests That Showed Startle and Flight Behavior for Each Run During the Motor and Sound Testing.

7 Vector Movement in the X-Y Direction During the Control Period

8 Vector Movement in the X-Y Direction for Each Test While the Sound was On

9 The Mean Vectors and Variance Ellipses at Each of the Six Centered Locations of the Pen for Each Species During the Control Periods .....

10 The Mean Vectors and Variance Ellipsis at Each of the Six Centered Locations of the Pen for Each Species While the Sound was On

11 Each Plot Displays the Proportion of Tests That Showed Moderate or Great Movement for Each Run During the First and Second Strobe Light Tests.

12 Each Plot Shows the Proportion of Tests That Showed Startle Response for Each Run During the Second Strobe Light

13 Movement Vector Plots During the Control Period for RBT and WCNK.

14 Movement Vector Plots During the First Strobe, When the Strobe was Coming From the Front or Left Side of Plots, for Each Species.

15 Light Intensity Measurements Illustrating Strobe Light Adsorption in Clear Well Water and Turbid Water

16 Generic Irrigation Diversion Facility with Behavior Barrier Component. 


\section{Tables}

1 Species and Average Length of Test Fish Used During Sound Testing 1998

2 Movement Classification Grades for "Infrasound" and Grade Totals for

Each Species

3 Movement Classification Grades for "Motor Sound" and Grade Totals for

Each Species .

4 Movement Classification Grade Totals During Infrasound for Each Species During the First 5 Exposures and the Last 5 Exposures.

$5 \quad$ Fish Behavior During "Infrasound" Categorized as Startle Responses for

Each Species

6 Fish Behavior During "Motor Sound" Categorized as Startle Responses for

Each Species 


\section{Introduction}

The objective of this study was to evaluate the effectiveness of using underwater sound generators and high intensity strobe lights as a behavioral barrier for possible use at fish diversion facilities. We designed tests to determine if the behavior of juvenile salmonids Oncorhynchus spp., and eastern brook trout Salvelinus fontinalis could be changed using infrasound and strobe lights. The rational behind this concept is to use behavior barriers to prevent migrating fish from becoming entrained in diversion facilities or to quickly direct entrained fish into the fish return system. If the majority of the fish are directed away from becoming entrained, survival of outmigrating salmonids can be increased. Currently, physical barrier screens are used to prevent entrainment at most fish diversion facilities. Past evaluations show these facilities to be effective if current screening criteria are met and operating guidelines are followed (Neitzel et al.1990a). However, evaluations have also shown current criteria may not be effective for protecting very small fish (Neitzel et al. 1990b, Mueller et al. 1995). In an ongoing program funded by Bonneville Power Administration (BPA), the Pacific Northwest National Laboratory (PNNL) was asked to evaluate the design, construction, and operation of fish screens in Washington and Idaho. In conjunction with these studies PNNL investigated if infrasound and strobe lights could be used to enhance the effectiveness of these facilities.

There have been a considerable number of lab and field studies to determine the mechanisms responsible and behavior responses when fish are exposed to infrasound (Sand and Karlsen 1986; Karlsen 1992). The use of volume displacement sources (VDS) operating in the infrasonic range has gained attention over the past few years as a possible behavior barrier device. Avoidance behaviors have been documented in laboratory and field studies by Knudsen et al. (1992, 1994, and 1997) and (Mueller et al. 1998) using piston type VDS's. The rational behind these tests was to determine if sub-yearling salmonids would respond to infrasound with predictable patterns. These studies conclude that yearling and subyearling juvenile Atlantic salmon Salmo salar L., chinook salmon $O$. tshawytscha, and rainbow trout $O$. mykiss, exhibit avoidance responses when exposed to the near field of high particle acceleration infrasound. Knudsen found that smolts (>100 $\mathrm{mm}$ ) respond with an innate avoidance response when the local flow acceleration is greater than $10^{-2} \mathrm{~m} / \mathrm{s}^{2}$ at a frequency of $10 \mathrm{~Hz}$. These tests were replicated using smaller ( $<50 \mathrm{~mm}$ ) salmonids with similar results (Mueller et al. 1998).

Strobe lights also have been shown to be effective at producing avoidance responses in juvenile salmonids under certain environmental conditions (Ploskey and Johnson 1998, Ploskey et al.1998). Other studies indicate the life stage of fish is important as sensitivity to light changes with fish growth (Anderson et al. 1988, Fernald 1988). It is our hypothesis that sound or light could be used at juvenile fish screening facilities to enhance their effectiveness for protecting small fish from being entrained or impinged. To accept the hypothesis, small fish would have to respond in a predictable manner when subjected to infrasound or light stimulus. 


\section{Methods}

We placed caged fish in a large tank to test the response of juvenile salmonids and char to infrasound and strobe light stimuli. The sound or light producing devices were placed adjacent to the cage with sound/light directed toward one end of the cage. Using underwater video cameras, we recorded the behavior responses and movement patterns of the fish.

\section{Test Tank and Net Pen}

An outdoor steel reinforced, oval fiberglass fish tank, measuring $3 \mathrm{~m}$ wide x $7.3 \mathrm{~m}$ long x $1.8 \mathrm{~m}$ deep, was used for infrasound testing. The top portion of the tank was covered using a canvas tarp to create consistent lighting. Test fish were confined to a net pen constructed of $0.16 \mathrm{~cm}$ nylon netting, measuring $1 \mathrm{~m}$ wide x $2 \mathrm{~m}$ long x 1.5 deep, attached to a 2.54-cm-diameter PVC frame with holes drilled in the bottom and side supports to aid in submergence of the frame. The x-axis advanced horizontally across the pen $(2 \mathrm{~m})$; the y-axis vertically $(1.5 \mathrm{~m})$; and the "z-axis" from back to front (Figure 1).

Gridlines were placed along the back wall, left wall (side with the sound source), floor, and ceiling of the pen to facilitate recording the fish responses. This is shown in Figure 1 as dotted lines. The gridlines were placed $0.33 \mathrm{~m}$ apart. The coordinate system starts in the back-bottom-left corner as $(0,0,0)$ and each gridline is considered one "grid unit." There are 6 grid units on the $\mathrm{x}$ axis, 4 grid units on the y axis, and 3 grid units on the $\mathrm{z}$ axis. The front-top-right corner is determined to be $(6,4,3)$ on the coordinate system.

\section{Video Equipment}

The video recording system consisted of high-resolution monochrome cameras (Sony, model HVM-352 ${ }^{1}$ ) with a wide-angle lens $\left(110^{\circ}\right)$ connected to an 8-mm camcorder (Sony model CCD-FX710 Handycam Hi8). Three underwater video cameras were used to document and record fish movement. Two cameras views that overlapped were positioned to record movement in the X, Y plane and the third was placed at the back of the pen to record movement in the $\mathrm{Z}$ plane. Video cameras operated continuously during each test series. The three-video signals were multiplexed and displayed on a signal monitor and recorded to Hi 8-mm tape.

\footnotetext{
${ }^{1}$ We used brand names to describe some of the equipment used to conduct these tests. The use of brand names is not an endorsement by PNNL, BPA, or the authors. We used these names so readers could more clearly understand our methods
} 


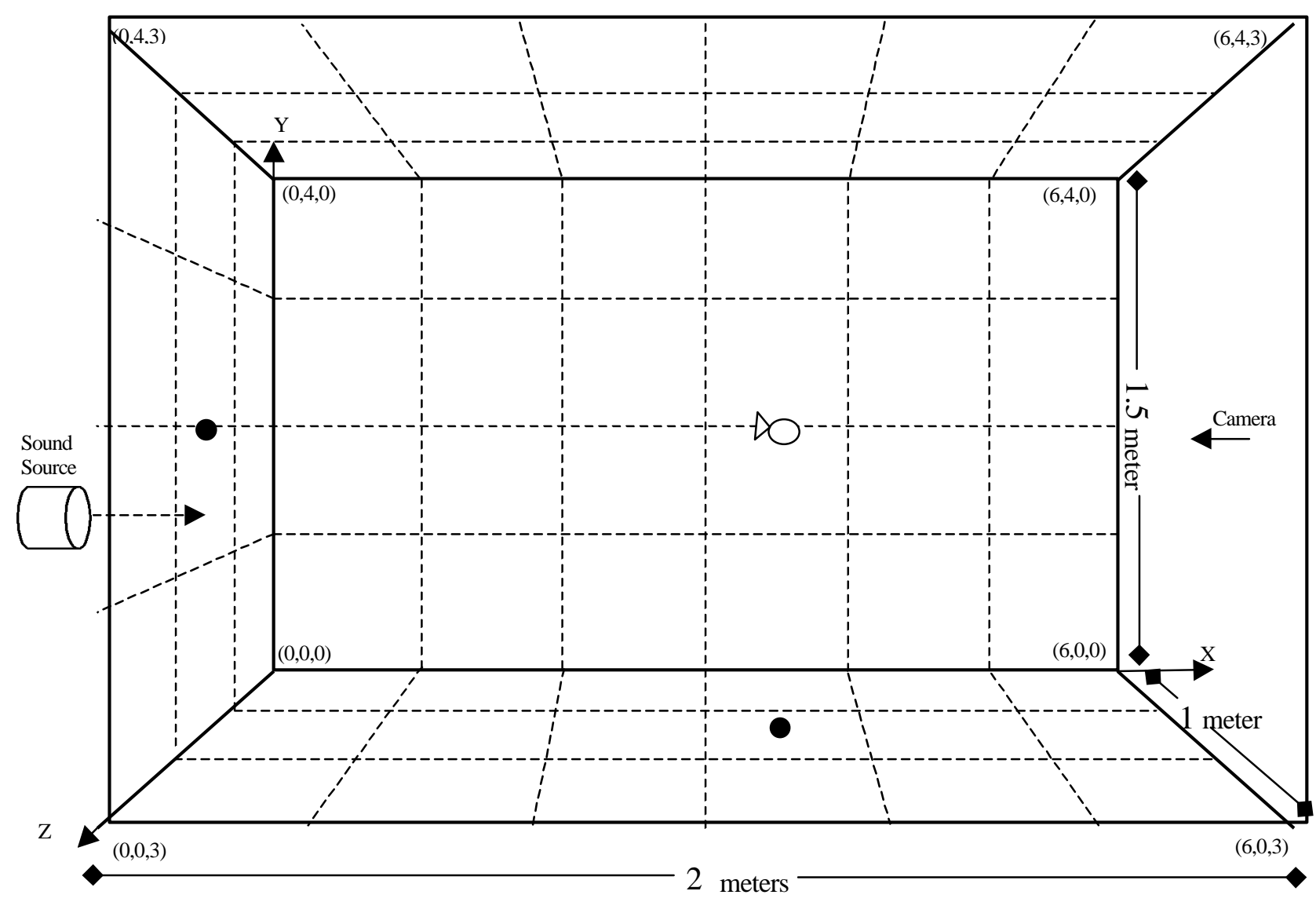

Figure 1. Birds Eye View of a 3-Dimensional Depiction of the Testing Pen. (The coordinate system starts in the bottom-back-left corner at $[0,0,0]$ and moves to the top-front-right corner at $[6,4,3])$.

\section{Test Fish}

The test fish used for the experiments consisted of wild and hatchery reared chinook salmon, hatchery rainbow trout, and hatchery eastern brook trout. The life stage ranged from swim up fry to larger smolts. Wild fall chinook salmon fry were seined from the Columbia River and ranged in length from (40-45 mm). Hatchery fall chinook salmon fry were raised from eggs obtained from the Priest Rapids State Fish Hatchery, Washington and were $(45-50 \mathrm{~mm}$ ) in length. Rainbow trout (Kamloop) fry were raised from eggs at the PNNL aquaculture facility and ranged in length from (25-44 mm). Two separate groups of eastern brook trout were used for the infrasound tests. The first group was obtained from Beitey Enterprises as sac fry and were $30-40 \mathrm{~mm}$ when tested; the second was obtained from the Spokane State Fish Hatchery, Washington and were 80-100 mm in length. All test fish were held in raceways or troughs and not fed for up to $10 \mathrm{~h}$ before being tested. Table 1 describes the test fish and sizes for tests completed in 1998. All test fish were acclimated to chilled well water $\left(14^{\circ} \mathrm{C}\right)$ before being transferred to the test tank. Acclimation in the test tank ranged from 3 to 15 hours. 
Table 1. Species and Average Length of Test Fish Used During Sound Testing 1998

\begin{tabular}{llllc}
\hline Infrasound & \multicolumn{1}{c}{ Species } & \multicolumn{1}{c}{ Date Tested } & \multicolumn{1}{c}{ Ave Size } & $\begin{array}{c}\text { Number of Test } \\
\text { Replicates }\end{array}$ \\
\hline \hline \multirow{5}{*}{ Strobe Light } & Rainbow trout & Spring 1998 & $25-44 \mathrm{~mm}$ & 22 \\
& Eastern brook trout & Spring 1998 & $30-40 \mathrm{~mm}$ & 7 \\
& Eastern brook trout & June 1998 & $80-100 \mathrm{~mm}$ & 7 \\
& Wild fall chinook & April/June 1998 & $40-45 \mathrm{~mm}$ & 23 \\
& salmon & & & \\
& Hatchery fall chinook & March 1998 & $45-50 \mathrm{~mm}$ & 24 \\
& salmon & & & \\
& Rainbow trout & April/May 1998 & $25-44 \mathrm{~mm}$ & 11 \\
& Eastern brook trout & May 1998 & $30-40 \mathrm{~mm}$ & 5 \\
& Wild fall chinook & April 1998 & $43 \mathrm{~mm}$ & 11 \\
& salmon & & & 10 \\
& Hatchery fall chinook & April/May 1998 & $45-50 \mathrm{~mm}$ & \\
& salmon & & & \\
\hline
\end{tabular}

\section{Infrasound Volume Displacement Source}

A high particle displacement, local flow infrasound field was generated in the test tank using a VDS built and designed by the University of Oslo, Norway. The components of the VDS included a piston diameter of $10 \mathrm{~cm}$ and a displacement amplitude (peak to peak) of $4.5 \mathrm{~cm}$. The VDS was operated within the frequency range 10-14 Hz. Water particle acceleration was achieved via the movement of two pistons located on opposite ends of the VDS. Horizontal particle acceleration curves for the VDS were mapped in 1996 and can be found in Mueller et al. (1998). The VDS was driven by an electric motor requiring 230-volt, three-phase power supply connected to a programmable power driver. A more detailed description of the VDS is given in Sand et al. (1998). The VDS (Figure 2) was suspended $1.6 \mathrm{~m}$ from one end of the tank and positioned $1 \mathrm{~m}$ off the bottom (measured to center of pistons). The support structure was isolated from the tank to eliminate any vibration transfer to the tank. One end of the net pen was positioned $0.8 \mathrm{~m}$ from the VDS with the piston axis located $0.5 \mathrm{~m}$ above the bottom of the net pen. Tests with the VDS were conducted from March through July 1998. 


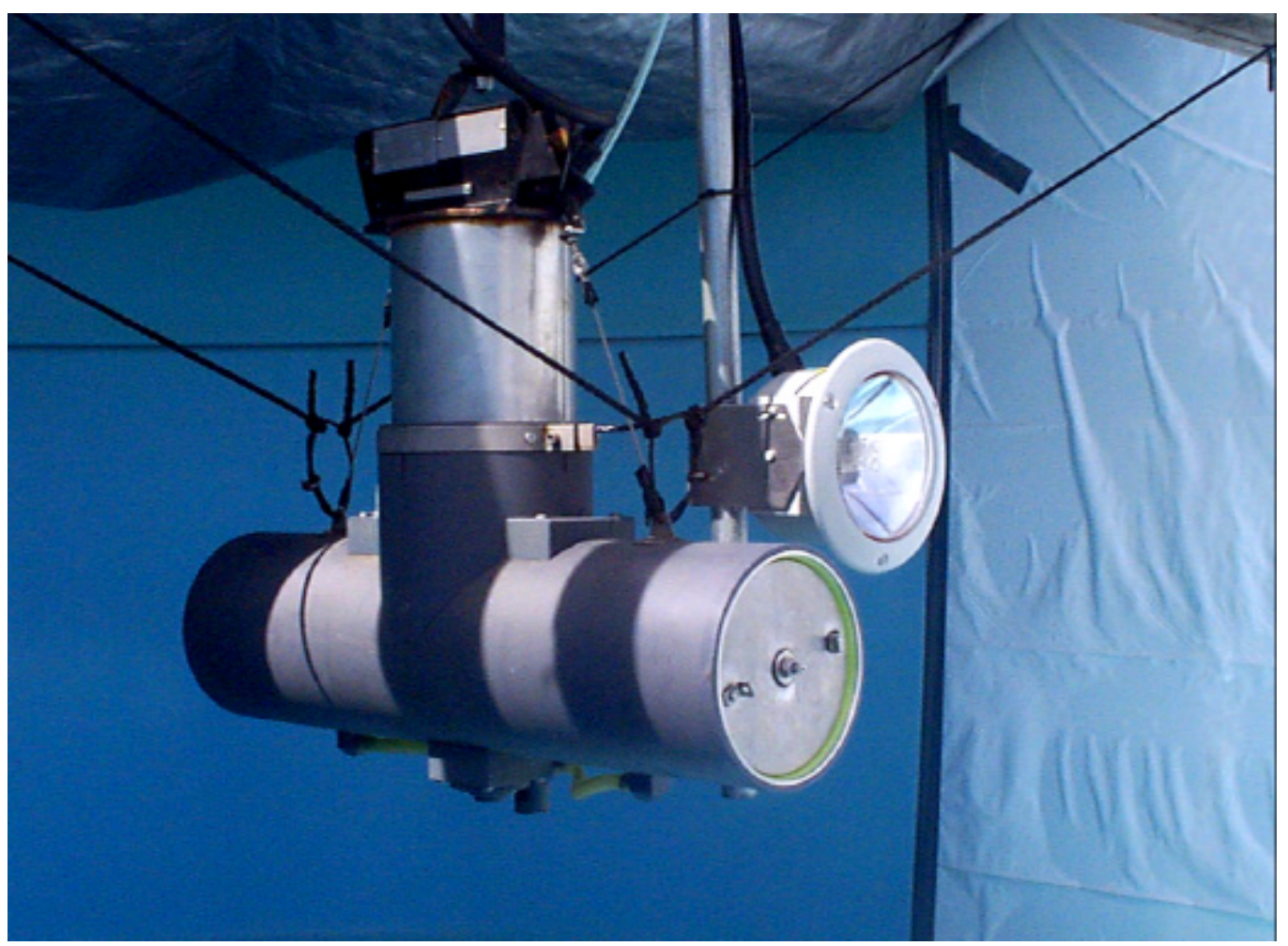

Figure 2. Photo of Infrasound VDS and Strobe Light Positioned in Test Tank

\section{Strobe Lights}

Tests were conducted with Flash Technology AGL 901 Aquatic Guidance Light. Initial tests were conducted with a signal strobe light positioned at one end of the net pen. A second strobe light was acquired about halfway through the test period. The strobe lights were mounted to an aluminum pole and positioned $\sim 0.8 \mathrm{~m}$ away from each end of the net pen then angled in a way to create more intense lighting in certain areas of the net pen (Figure 2). The strobe lights were connected to a control box, which allowed us to activate the lights and change the flash-rate. Strobe lights operated at $300 \mathrm{fpm}$ at 400 watts for most tests. Tests were conducted in April and May of 1998. Strobe light intensity measurements in lux were measured at $0.5 \mathrm{~m}$ interval to a maximum distance of $3.1 \mathrm{~m}$. Measurements were taken using a LI COR LI-188B photometer with an underwater Quantum Sensor Model LI-192S.

\section{Experimental Procedure}

Test protocol for the infrasound and strobe lights was similar. Each testing day consisted of three test cycles. The first cycle was in the morning (0700-0900 h); the second cycle ran late morning 
through the early afternoon (1100-1300 h); and the third cycle ran during the late afternoon (1400-1600 h). The testing scenario included a random selection of 10 stimuli over a 1-hour test period. A 3min minimum interval was used to separate reaction tests. A test cycle is outlined by the following steps with differences between treatments shown:

\section{Pre-Test Period}

Acclimation period. Test groups consisting of 20 fish were placed in the pen and remained in the pen for an acclimation period of at least 1 hour. The fish tested in the morning had an acclimation period of at least 15 hours, because they were placed in the pen the previous day. After the acclimation period all three cameras began to record. Prior to testing, test fish were held in covered troughs.

\section{Sound Test Period}

- Control period. During the time when no stimulus (sound, motor, or strobe) was being applied, control measurements were taken to record the general movement patterns of the caged fish. There was a control measurement taken before the first run, between each of the 10 runs, and one taken after the tenth run, for a total of 11 control measurements per test cycle. All of the control measurements were taken for a 20 -second interval between the "before" and "after" measurements and were taken randomly during the last minute before the stimulus was applied. Only the "before" and "after" measurements were recorded.

- Motor Sound On. The motor was turned on and pistons gradually increased in revolutions per minute (rpm) for a 5-15 second period. Once maximum rpm's were observed, the VDS remained on for 20 seconds and then was turned off. The test group's response to the motor noise was also graded for startle response and fish movement.

- $\quad$ The test period was repeated nine more times, for a total of ten replications (runs).

\section{Strobe Test Period}

- Control period. Control responses were recorded identical to the sound control period (see above).

- $\quad$ First Strobe on. The first strobe turned on for a 20-second period from a randomly determined end of the pen.

- $\quad$ Second Strobe on. The first strobe was turned off, and the opposite strobe turned on for a 20 -second period and was then turned off. The second strobe light was not used with the first eight tests in the experiment.

- $\quad$ The test period was repeated nine more times, for a total of ten replications (runs).

\section{Sampling Responses and Data Collection}

For each test group, we evaluated the response of a school of fish by measuring gross movement of the center of the school before and immediately after the behavior stimuli. Non-schooled 
were excluded from this determination and a minimum school contained at least eight individuals for inclusion in the analysis. Tapes were reviewed and analyzed by measuring the school movement and other fish behavior including startle and avoidance behavior.

- "Before" measurements. The location on the center of a school was recorded by using the grid coordinates described in Figure 1. Coordinate values were estimated to the nearest half grid unit.

- "After" measurements. Immediately after the stimulus event period, the tape was stopped and the coordinate estimated for the location of the center of the school.

- Movement classification. After each set of "before" and "after" measurements during a treatment (motor on, sound on, or strobe on), the displacement of the school during the event was classified by the evaluator into one of the following 4 categories (grades):

- $\quad$ no response less than $0.15 \mathrm{~m}(\mathrm{~N})$, slight - movement of 0.15-0.3 m (S)

- $\quad$ moderate - movement of 0.3-0.6 m (M)

- $\quad$ and great - movement of $0.6 \mathrm{~m}$ or more $(\mathrm{G})$.

These categories were selected to determine the extent of movement (avoidance) within the confines of the net pen.

- Startle/flight classification. After each set of "before" and "after" measurements, the evaluator also observed the school reaction to the stimulus. This reaction was observed to determine if the fish exhibited startle and flight behaviors, which we characterized as a rapid abrupt movement away from the source.

- Habituation. Observations were made to determine if and when the school became habituated to the stimulus. Habituation was defined as no avoidance behavior or movement toward the stimulus. 


\section{Results}

\section{Infrasound (Volume Displacement Sources)}

Response to an infrasound stimulus by fish varied with species and age. Chinook salmon are more likely to respond to infrasound while small rainbow and eastern brook trout may not respond to infrasound.

\section{Chinook Salmon}

Test results suggested that wild chinook salmon are much more likely to respond to the VDS than hatchery reared fish. Age and size of the fish tested were similar for all test groups. Based on past experiments with infrasound, test fish would habituate to the sound stimulus after repeated exposures. This habituation behavior is evident in our tests as the greatest avoidance responses occurred during the initial exposures, then dropped off significantly after the fifth exposure. Wild chinook salmon fry were more likely to be deterred and avoid the VDS (near $70 \%$ of the test groups) during the first few exposures. Avoidance responses dropped off to near $50 \%$ after the fourth exposure. Hatchery chinook salmon had a high initial response, but avoidance response decreased rapidly to near $20 \%$ after the fourth exposure. Startle response for chinook salmon was fairly consistent between the wild and hatchery fish, although wild chinook salmon exhibiting a startle response near $50 \%$ for the initial exposures.

\section{Rainbow Trout Fry}

Rainbow trout fry showed no observable avoidance responses to the onset of the VDS, although a startle response or "flash expansion" was observed with $16 \%$ of the first five test exposures. The control group movements were not significantly different than the test responses.

\section{Eastern Brook Trout}

Test groups of eastern brook trout displayed the least behavior responses to the infrasound VDS. Their movement was classified as none to slight for all test groups. No significant differences were observed between the two size groups tested. Other behavior responses including startle or expansion were not observed. 


\section{A. Movement Classification Grades}

The classification grades for each species tested during the Infrasound testing and the motor sound testing are found in Tables 2 and 3 . Test fish were not influenced by the sound generated by the start of the motor. Wild and hatchery reared chinook salmon displayed the majority of great/ moderate movement away from the VDS, while rainbow trout and eastern brook trout did not seem affected by the VDS.

Table 2. Movement Classification Grades for Infrasound Testing and Grade Totals for Each Species

\begin{tabular}{lccccccc}
\hline \multicolumn{1}{c}{ Species } & (a) & (b) & (c) & None & Total & $\begin{array}{c}\text { Percentage } \\
\text { Any } \\
\text { Movement }\end{array}$ & $\begin{array}{c}\text { Percentage Great } \\
\text { or Moderate } \\
\text { Movement }\end{array}$ \\
\hline \hline $\begin{array}{l}\text { Eastern brook } \\
\text { trout }\end{array}$ & 6 & 2 & 1 & 125 & 134 & $7 \%$ & $2 \%$ \\
$\begin{array}{l}\text { Hatchery } \\
\text { chinook }\end{array}$ & 42 & 23 & 7 & 154 & 226 & $32 \%$ & $13 \%$ \\
$\begin{array}{l}\text { Rainbow trout } \\
\text { Wild chinook }\end{array}$ & 30 & 1 & 0 & 209 & 213 & $2 \%$ & $0.5 \%$ \\
\hline
\end{tabular}
(a) Slight movement $0.15-0.3 \mathrm{~m}$.
(b) Moderate movement $0.3 \mathrm{~m}-0.6 \mathrm{~m}$.
(c) Strong movement $>0.6 \mathrm{~m}$.

Table 3. Movement Classification Grades for Motor Sound Testing and Grade Totals for Each Species

\begin{tabular}{lccccccc}
\hline \multicolumn{1}{c}{ Species } & (a) & (b) & (c) & None & Total & $\begin{array}{c}\text { Percentage } \\
\text { Any } \\
\text { Movement }\end{array}$ & $\begin{array}{c}\text { Percentage Great } \\
\text { or Moderate } \\
\text { Movement }\end{array}$ \\
\hline \hline $\begin{array}{l}\text { Eastern brook } \\
\text { trout }\end{array}$ & 2 & 0 & 0 & 134 & 136 & $1 \%$ & $0 \%$ \\
$\begin{array}{l}\text { Hatchery chinook } \\
\text { Rainbow trout }\end{array}$ & 10 & 6 & 1 & 209 & 226 & $8 \%$ & $3 \%$ \\
Wild chinook & 5 & 1 & 0 & 212 & 213 & $0.5 \%$ & $0.5 \%$ \\
\hline
\end{tabular}
(a) Slight movement $>0.6 \mathrm{~m}$.
(b) Moderate movement $0.3 \mathrm{~m}-0.6 \mathrm{~m}$.
(c) Great movement $0.15-0.3 \mathrm{~m}$. 
Our investigation showed that this movement response decreased as the fish were exposed to the sound. Table 4 separates the first five runs and the last five runs for each test and indicates the movement grades for the sound treatment. We see a significant drop in the rate of movement percentages from the first five runs to the last five runs, showing that the fish are becoming habituated as the exposure increases. As the number of times the fish were exposed increases, the movement decreases (Figure 3). The chinook salmon fry were habituated generally after the fourth exposure to the VDS. Analysis of variance was performed on the percentage of any movement and the percentage of great/moderate movement during the sound. In both analyses, significant differences were found between the species and also between the runs (exposures). All p-values were below the 0.001 level.

Table 4. Movement Classification Grade Totals During Infrasound for Each Species During the First Five Exposures (runs) and the Last Five Exposures (runs)

\begin{tabular}{|c|c|c|c|c|c|c|c|}
\hline Species & (a) & (b) & (c) & None & Total & $\begin{array}{c}\text { Percentage } \\
\text { Any } \\
\text { Movement }\end{array}$ & $\begin{array}{c}\text { Percentage Great } \\
\text { or Moderate } \\
\text { Movement }\end{array}$ \\
\hline \multicolumn{8}{|l|}{ First 5 Runs } \\
\hline $\begin{array}{l}\text { Eastern brook } \\
\text { trout }\end{array}$ & 5 & 1 & 1 & 62 & 69 & $10 \%$ & $3 \%$ \\
\hline Hatchery chinook & 33 & 17 & 4 & 64 & 118 & $46 \%$ & $18 \%$ \\
\hline Rainbow trout & 3 & 1 & 0 & 105 & 109 & $4 \%$ & $1 \%$ \\
\hline Wild chinook & 30 & 24 & 23 & 35 & 112 & $69 \%$ & $42 \%$ \\
\hline \multicolumn{8}{|l|}{ Second 5 Runs } \\
\hline $\begin{array}{l}\text { Eastern brook } \\
\text { trout }\end{array}$ & 1 & 1 & 0 & 63 & 65 & $3 \%$ & $2 \%$ \\
\hline Hatchery chinook & 9 & 6 & 3 & 90 & 108 & $17 \%$ & $8 \%$ \\
\hline Rainbow trout & 0 & 0 & 0 & 104 & 104 & $0 \%$ & $0 \%$ \\
\hline Wild chinook & 20 & 14 & 5 & 68 & 107 & $36 \%$ & $18 \%$ \\
\hline
\end{tabular}
(a) Slight movement $>0.6 \mathrm{~m}$.
(b) Moderate movement $0.3 \mathrm{~m}-0.6 \mathrm{~m}$.
(c) Great movement $0.15-0.3 \mathrm{~m}$. 

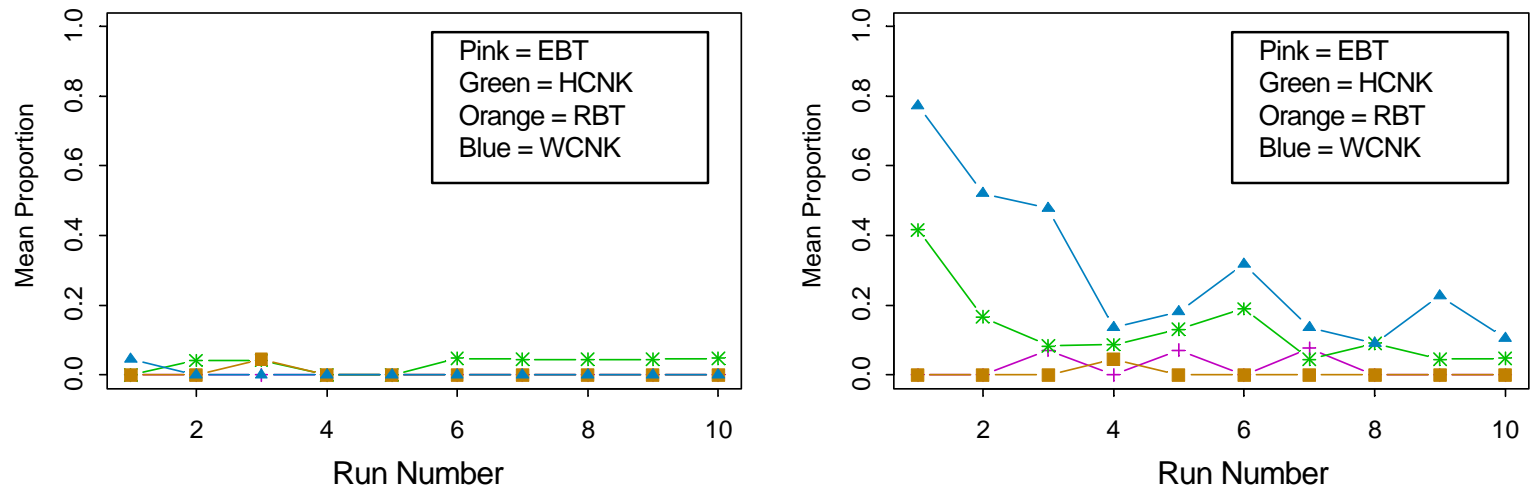

Figure 3. The Proportion of Tests That Showed Moderate/Great Movement for Each Exposure (run) During Motor and Sound Testing

Two age groups of eastern brook trout were used to determine if infrasound could illicit behavior responses. Initially 7 tests consisting of 10 exposures each were conducted with 40-mm fry. Results from these tests showed $90 \%$ of the test exposures exhibited no avoidance. To eliminate any potential bias concerning this particular strain of brook trout, a new test group (80-100 $\mathrm{mm}$ in length) was obtained from another hatchery. Although the instances of moderate/great movement were rare $(<$ $20 \%$ ), all of the times movement was detected were with the larger eastern brook trout. It is interesting that this movement occurred every other exposure (Figure 4).

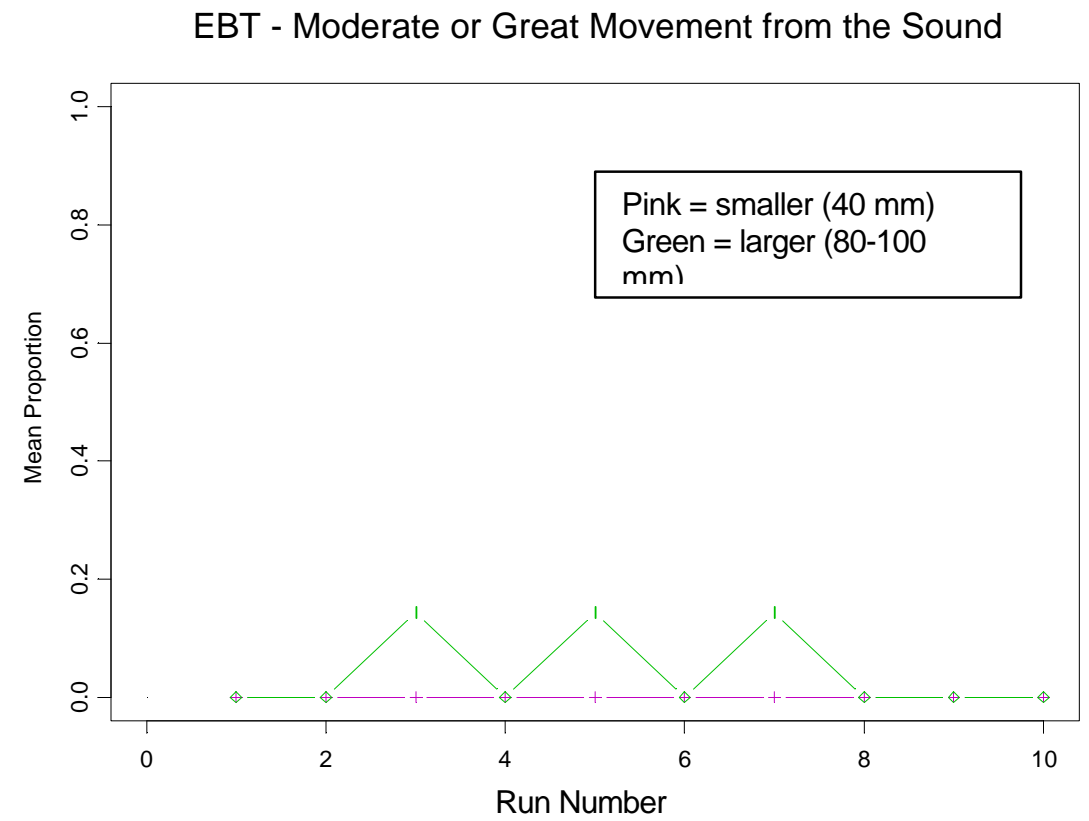

Figure 4. The Proportion of Tests Which Showed Moderate or Great Movement for Eastern Brook Trout 
The infrasound testing periods were separated into two basic time periods: the tests in which the fish were tested the same day (2-3 hour acclimation) that they were put into the net pen, and the tests in which the fish were tested the day after they were put into the net pen (12-15 hour acclimation). The data indicates that for wild chinook salmon the average moderate/great movement proportion was 0.48 for the same day tests compared to 0.30 for the next day tested fish (first 6 exposures). The p-value for the difference was 0.033 . For hatchery chinook salmon the average moderate/great movement was 0.24 for the same day tests compared to 0.11 for the next day tests (first 6 exposures). The p-value was 0.046. Avoidance responses for wild and hatchery chinook salmon decreased significantly after the first six exposures indicating the test groups becoming habituated to the sound stimulus (Figure 5). No significant differences were observed when comparing acclimation time to fish response for rainbow trout and eastern brook trout.

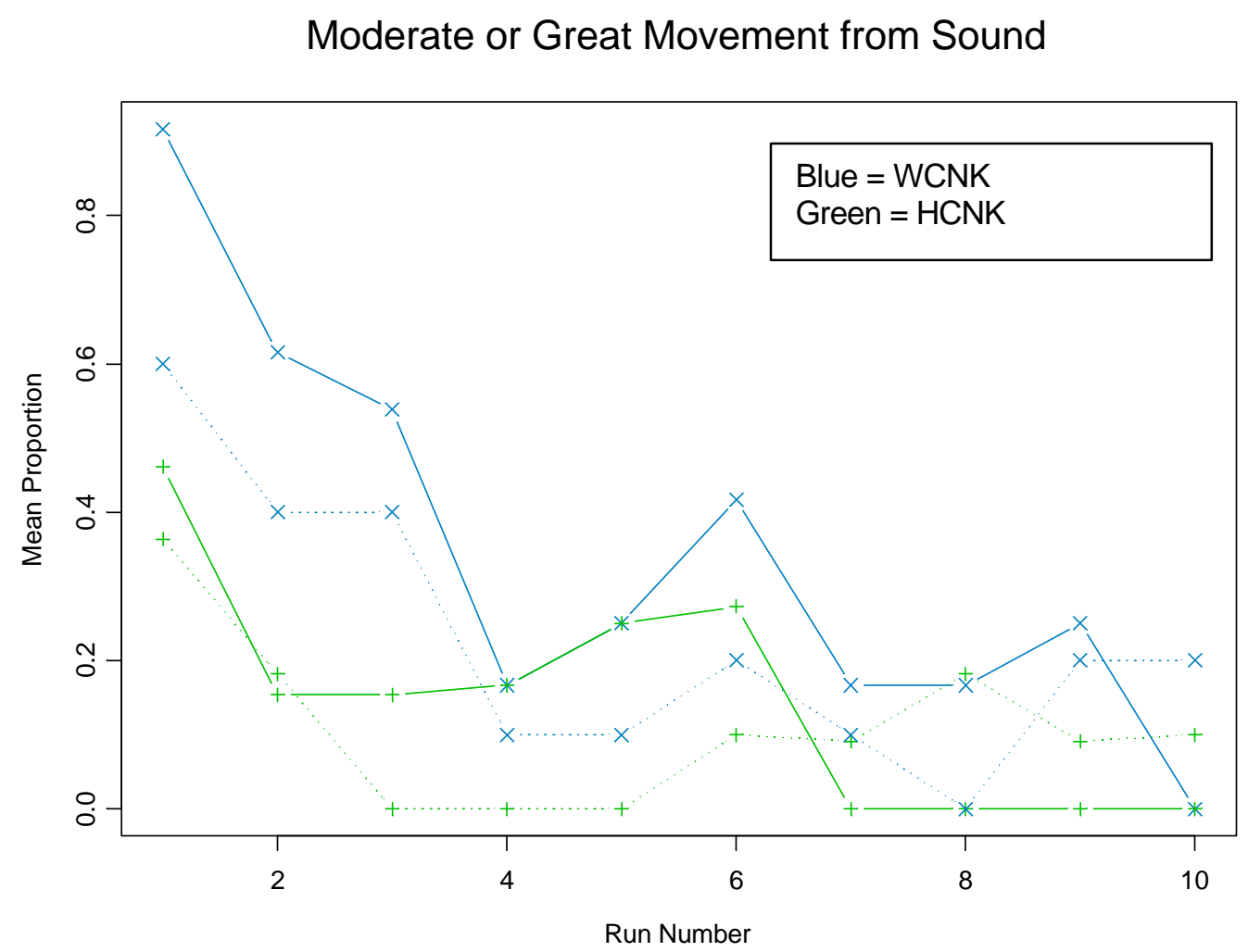

Figure 5. A Proportion of the Tests Where Moderate/Great Movement was Detected During the Sound Testing. The solid line represents a 2-3 $\mathrm{h}$ acclimation period and the dashed line represents a 12-15 $\mathrm{h}$ acclimation period for each test group. 


\section{B. Startle Responses}

The results of this classification during the sound on testing and the motor on testing are found in Tables 5 and 6. Similar to avoidance movement, the chinook salmon (hatchery and wild) displayed the majority of the startle and flight responses to infrasound (27\% and $26 \%$ respectfully). The startle responses were more evident during the initial exposures and were characterized by a response away from the VDS usually towards deeper water. Startle responses were less apparent after the fifth exposure.

\section{Movement Vectors}

During the treatments (sound on and motor on) and the control period, "before" and "after" measurements were taken on the location of the school for each species. This was done to graphically show the movement during each of these periods and to help compare the type of movement during a treatment to the normal movement (control period). Vector movements during the control measurements show general random movement patterns (Figure 7). During the sound on, vector movement for wild chinook salmon was generally down and away for groups that were nearest the VDS and

Table 5. Fish Behavior During Infrasound Testing Categorized as Startle Responses for Each Species

\begin{tabular}{lcccc}
\hline & Startle & None & Total & Percent Startle \\
\hline \hline $\begin{array}{l}\text { Eastern brook } \\
\text { trout }\end{array}$ & 1 & 123 & 135 & $0.7 \%$ \\
Hatchery chinook & 40 & 128 & 226 & $27 \%$ \\
Rainbow trout & 22 & 185 & 213 & $11 \%$ \\
Wild chinook & 16 & 88 & 219 & $26 \%$ \\
\hline
\end{tabular}

Table 6. Fish Behavior During Motor Sound Testing Categorized as Startle Responses for Each Species

\begin{tabular}{lcccc}
\hline \multicolumn{1}{c}{ Species } & Startle & None & Total & Percent Startle \\
\hline \hline $\begin{array}{l}\text { Eastern brook } \\
\text { trout }\end{array}$ & 1 & 134 & 136 & $0.7 \%$ \\
Hatchery chinook & 3 & 209 & 226 & $1 \%$ \\
Rainbow trout & 2 & 210 & 213 & $0.9 \%$ \\
Wild chinook & 0 & 213 & 219 & $0 \%$ \\
\hline
\end{tabular}


Startle Response when Motor on

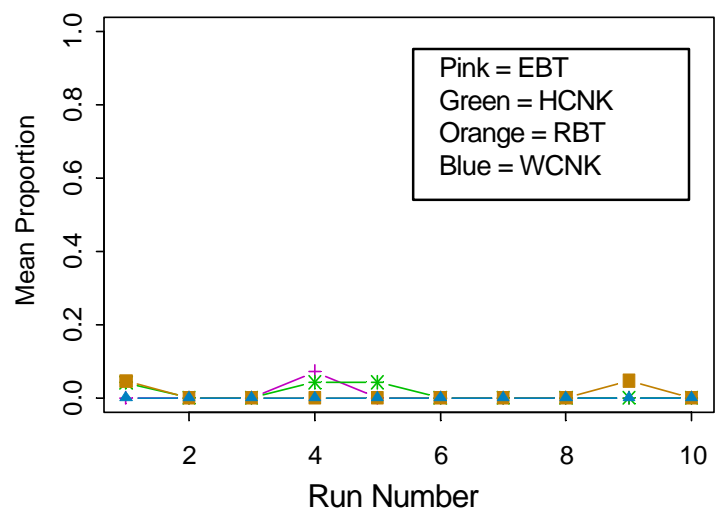

Startle Response when Sound on

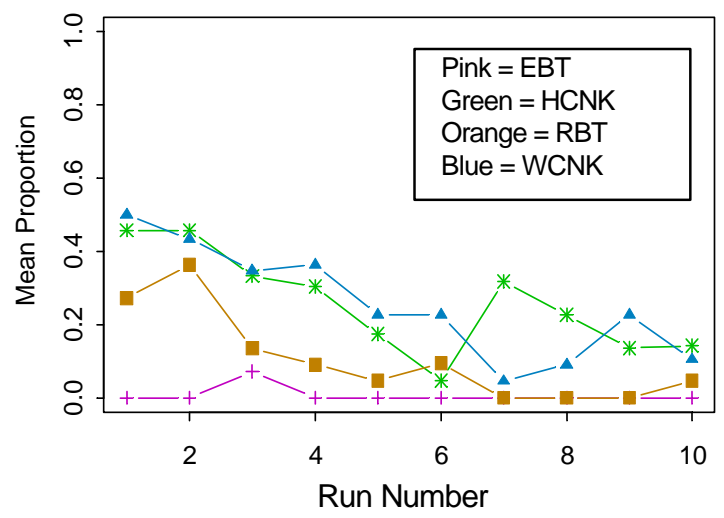

Figure 6. Each Plot Shows the Proportion of Tests That Showed Startle and Flight Behavior for Each Run (exposure) During the Motor and Sound Testing

Brook Trout - control

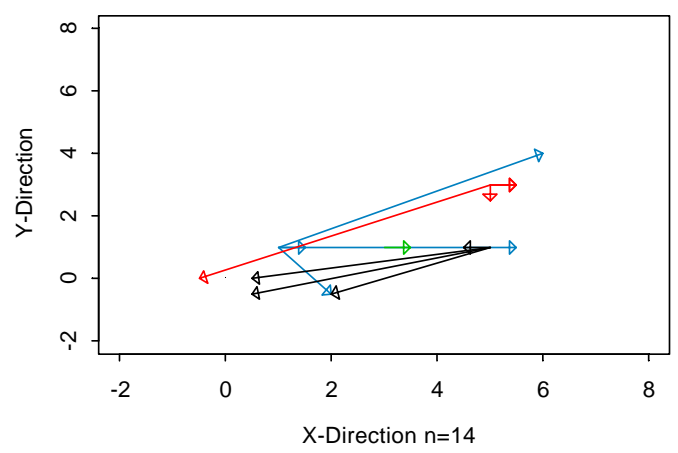

Rainbow Trout - control

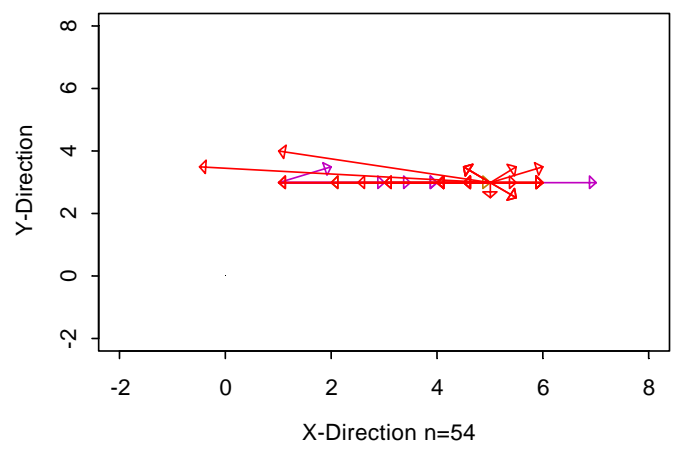

Hatchery Chinook - control

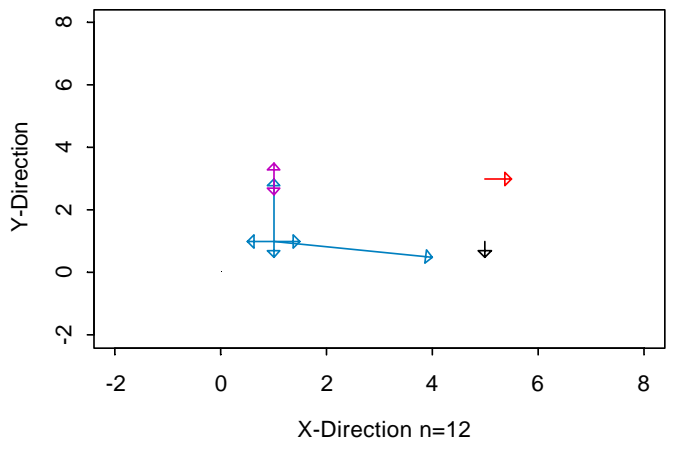

Wild Chinook - control

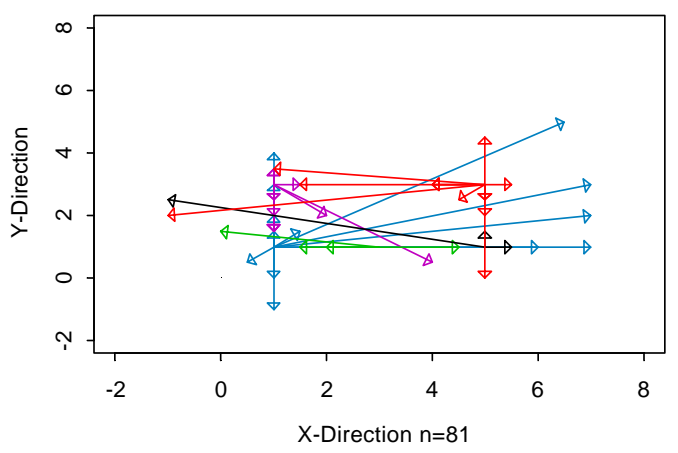

Figure 7. Vector Movement in the X-Y Direction During the Control Period (no treatment). The different colors represent six different starting locations. All vectors were centered and started from the closest of the six locations. The locations indicated in parens are in $\mathrm{x}, \mathrm{y}$ notation: (1,1)-blue, (1,3)-purple, $(3,1)$-green, $(3,3)$-orange, $(5,1)$-black, and $(5,3)$-red. 
toward the VDS when fish were located furthest from the VDS (Figure 8). The movement toward the VDS by wild chinook salmon was observed after repeated exposures to the VDS and is an example of habituation. These measurements required a center location of the school, so measurements could only be taken during those times when schooling occurred. Each figure gives the sample sizes in which this occurred. The wild chinook salmon was the only species that maintained a consistent school, as can be seen from the larger sample sizes.

In addition to vector movement, variance ellipse plots for each of the average vectors were created that indicate the area in which $90 \%$ of the vectors fell. The average vectors for each control group from each of six centered locations show movement during this time tends to be towards the middle of the pen (Figure 9). During the sound on tests the vectors would be expected to travel to
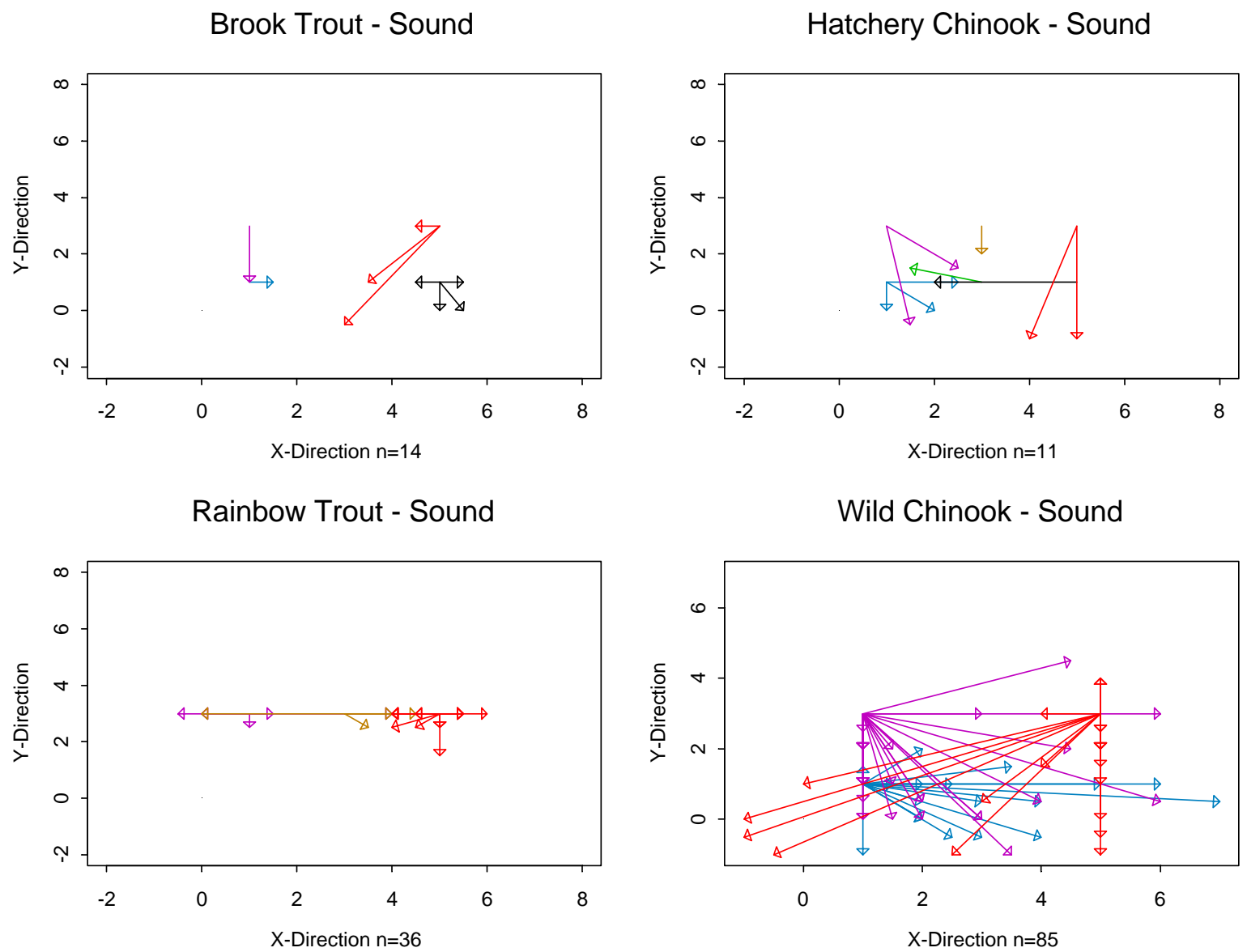

Figure 8. Vector Movement in the X-Y Direction for Each Test While the Sound was On. The different colors represent six different starting locations. All vectors were centered and started from the closest of the six locations. The locations indicated are in x,y notation: (1,1)-blue, (1,3)-purple, (3,1)-green, (3,3)-orange, (5,1)-black, and (5,3)-red. 

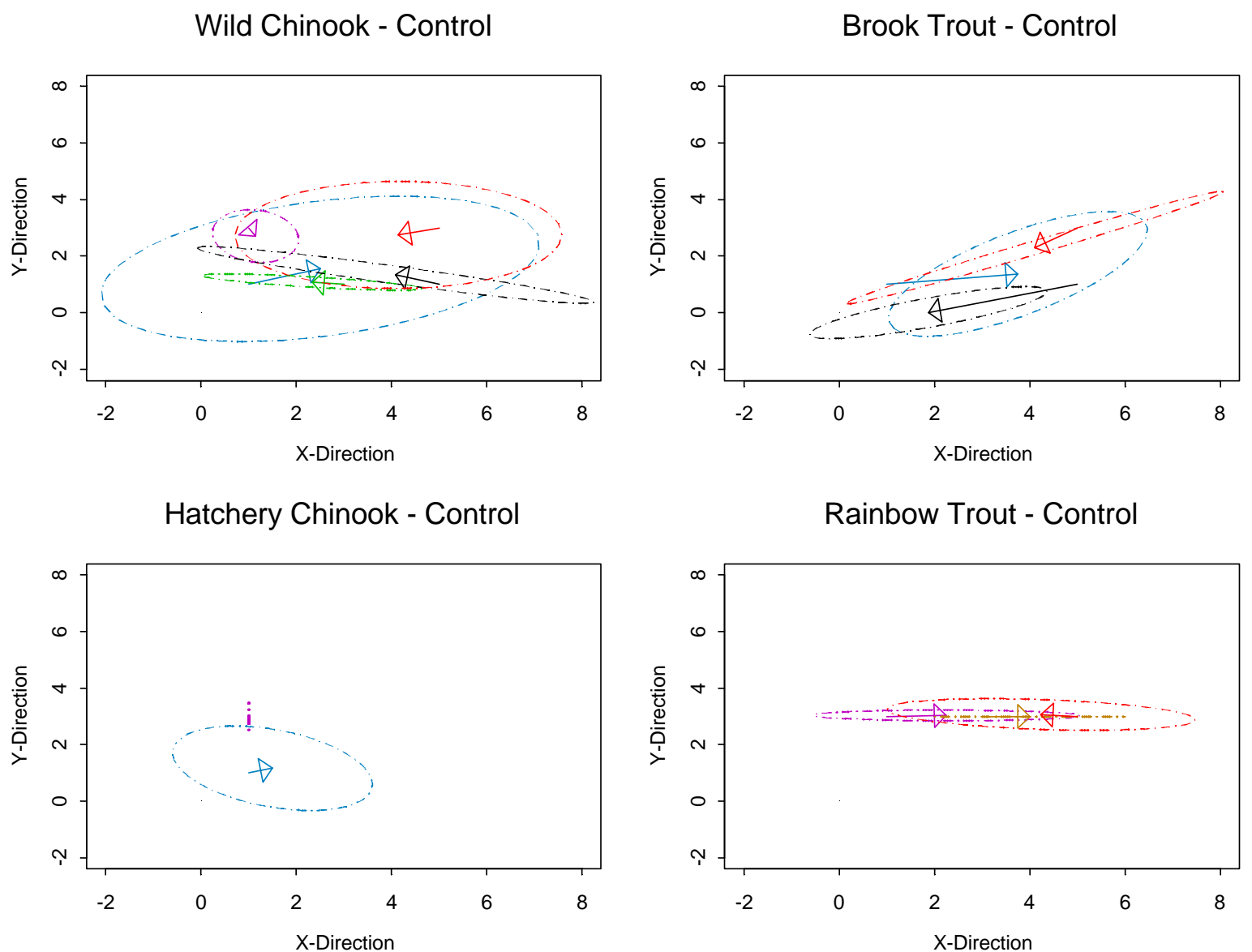

Figure 9. The Mean Vectors and Variance Ellipses at Each of the Six Centered Locations of the Pen for Each Species During the Control Periods

the right. The movement classification grades showed that the chinook salmon were most likely to move due to the sound. Their movement shown in Figure 10 is generally down and usually to the right (except for those who started on the far right). The down movement may also be an indication of the fishes desire to move away from the sound.

A comparison between the mean vectors for the control and the test period for wild chinook salmon indicate that when the sound is on the wild chinook salmon are diving toward the bottom of the pen. The control plot at the same position shows the wild chinook salmon go down a little, but not nearly at the same magnitude. At position $y=1$, even though the wild chinook salmon are near the bottom of the pen, they dive down a small amount during the sound. Likewise, the control plot shows the wild chinook salmon moved from the same position in an upward trend. At position 

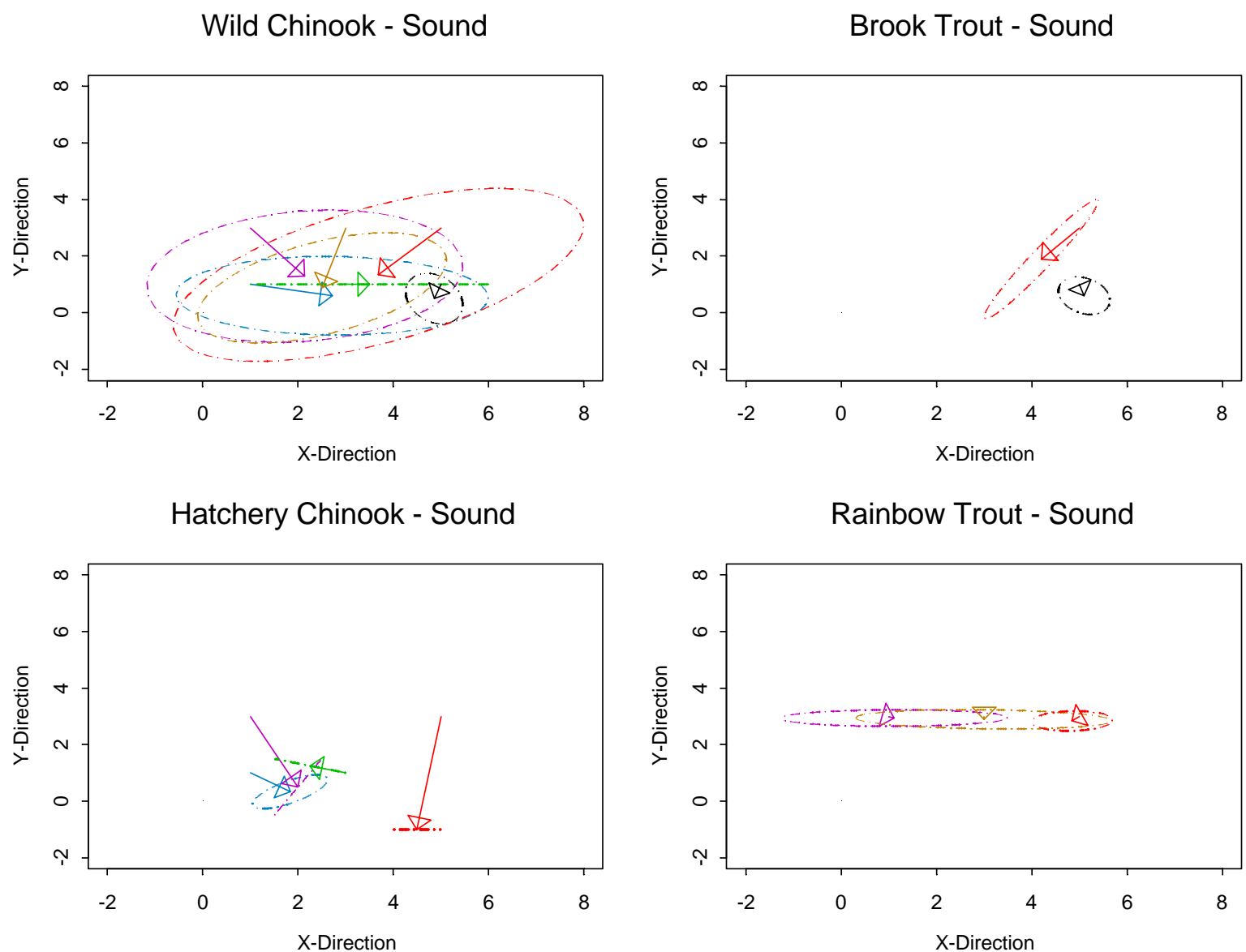

Figure 10. The Mean Vectors and Variance Ellipsis at Each of the Six Centered Locations of the Pen for Each Species While the Sound was On

$\mathrm{x}=1$, the movement of the wild chinook salmon during the sound is down and significantly away from the sound. During the control period, the movement away from the sound isn't as pronounced, and in some tests the movement is upward. At the position $\mathrm{x}=5$, the movement of the wild chinook salmon during the sound is down toward the bottom, while the control period movement is toward the center of the pen. These comparisons give strong indication that the wild chinook salmon are responding to the sound and tend to move away from it. 


\section{Strobe Light Analysis}

Responses to high intensity strobe light stimulus again varied on species tested. Chinook salmon and rainbow trout are more likely to respond to strobe light, while small eastern brook trout did not respond to strobe lights.

\section{Chinook Salmon}

Our results indicate wild chinook salmon fry were more likely to demonstrate avoidance and to display startle responses when exposed to strobe lights than hatchery chinook salmon. General responses for wild chinook salmon included avoidance responses and a generalized schooling behavior was observed during the acclimation period. When the strobe light was activated the response was characterized by a startle response followed by a flight path away from the strobe usually to a lower corner furthest away from the light source.

\section{Rainbow Trout Fry}

Rainbow trout fry had a strong avoidance response, which included an initial startle behavior followed by a flight path away from the light source. Little if any habituation was observed during a series of 10 exposure (runs) tests.

\section{Eastern Brook Trout}

A series of five tests were conducted using eastern brook trout fry $(30-40 \mathrm{~mm})$. In all tests no observable avoidance or startle response was apparent to the abrupt, high intensity strobe light. Test group acclimation periods in the test tank ranged from 3 hours to 2 days. Neither the acclimation period nor times of day fish were tested resulted in any differences in fish response.

\section{A. Movement Classification Grades}

Rainbow trout and chinook salmon were most likely to respond with avoidance behaviors during activation of the strobe lights (Figure 11). These plots again indicate that the chinook salmon (wild and hatchery) displayed a significant proportion of movement. The rainbow trout showed a high proportion of movement due to the first strobe, while the eastern brook trout showed hardly any movement from the strobe lights ( 1 of 5 test groups at most showed movement). Unlike the sound tests, the movement due to the strobe did not decrease as the number of exposures increased (up to 10 exposures), which indicates fish did not habituate to the light. 
A visual comparison of the first light movement to the second light movement shows differences. The movement reaction (moderate and great) was larger to the first strobe than the second strobe; however, both strobes caused significant proportions of movement for the chinook salmon and rainbow trout. In both cases the eastern brook trout did not appear to react to the lights.

\section{B. Startle Responses}

Startle responses elicited by the activation of the strobe lights were evident for to some degree in all species tested with the exception of eastern brook trout. The proportion of each species that displayed any startle reactions during the first strobe light ranged from $0 \%$ for eastern brook trout to near $30 \%$ for hatchery chinook (Figure 12$)$. The sample sizes were $(n=5,9,11, \& 9)$. The startle reaction appeared small but still significant for the rainbow trout and hatchery and wild chinook salmon. Once again, the startling responses did not decrease as the number of exposures increased (up to 10 exposures).

The second strobe was tested after the first eight tests. The sample sizes were $(\mathrm{n}=5,8,11$, and 2$)$. The startle reaction appeared small but still significant for the hatchery chinook salmon and rainbow trout. When subjected to the second strobe, the startle behaviors did not decrease as the number of exposures increased (Figure 12). A visual comparison of the first light startling to the second light startling shows the reaction of each of the species tends to be similar, unlike the movement classification grades. 


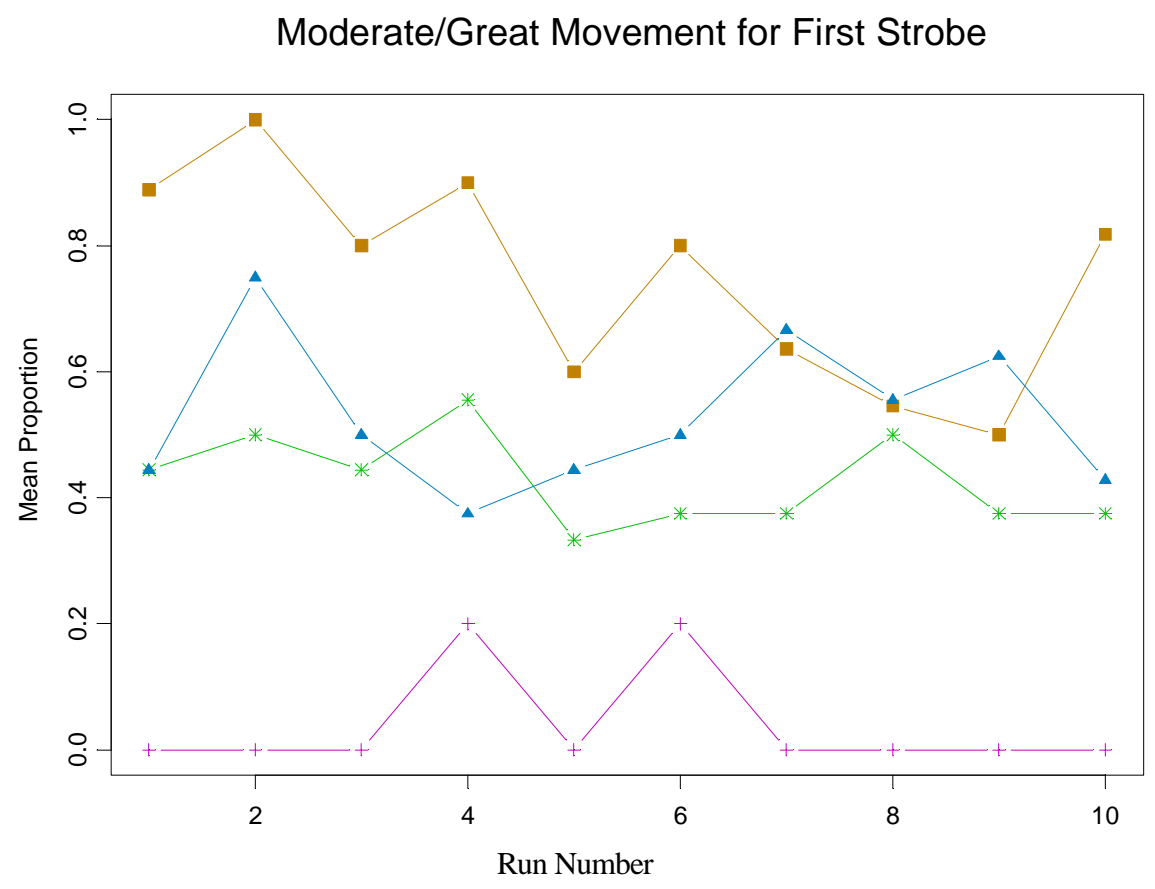

Pink $=$ EBT $(n=5)$, Green=HCNK $(n=9)$, Orange=RBT $(n=11)$, Blue=WCNK $(n=9)$

Moderate/Great Movement for Second Strobe

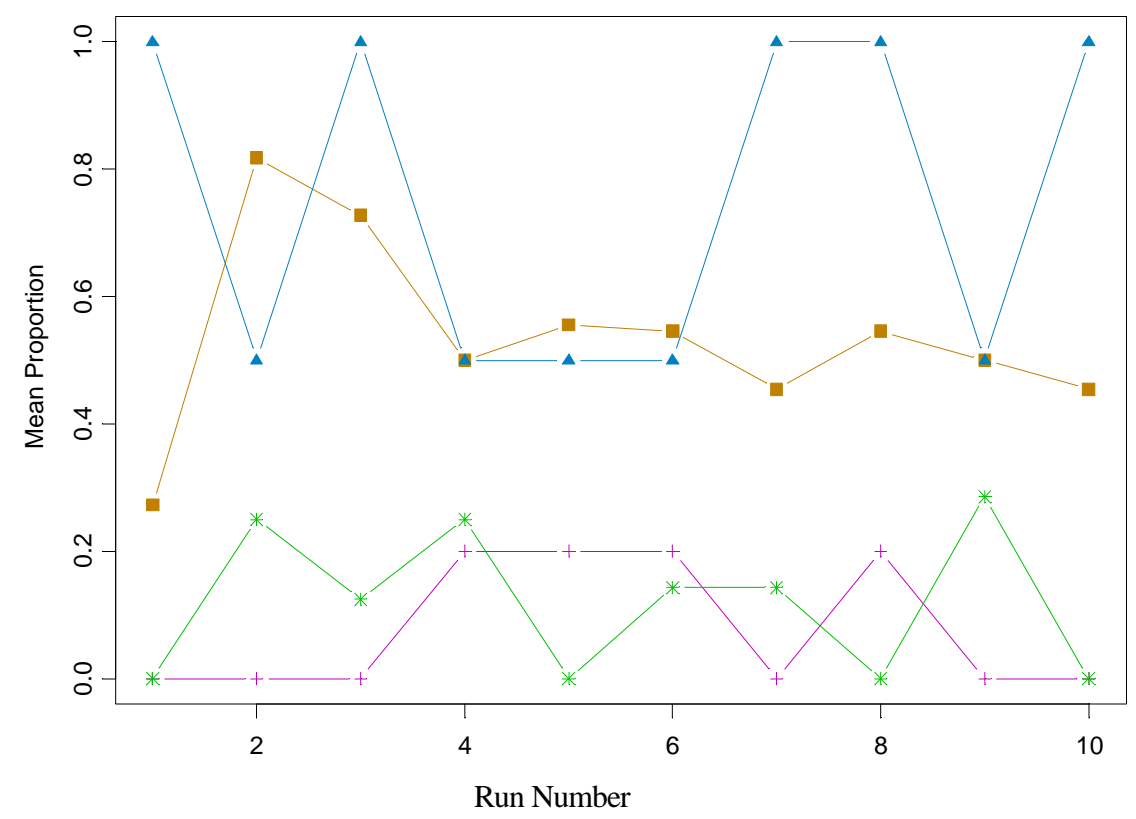

Pink $=$ EBT $(n=5)$, Green $=$ HCNK $(n=8)$, Orange=RBT $(n=11)$, Blue $=$ WCNK $(n=2)$

Figure 11. Each Plot Displays the Proportion of Tests That Showed Moderate or Great Movement for Each Run During the First and Second Strobe Light Tests 

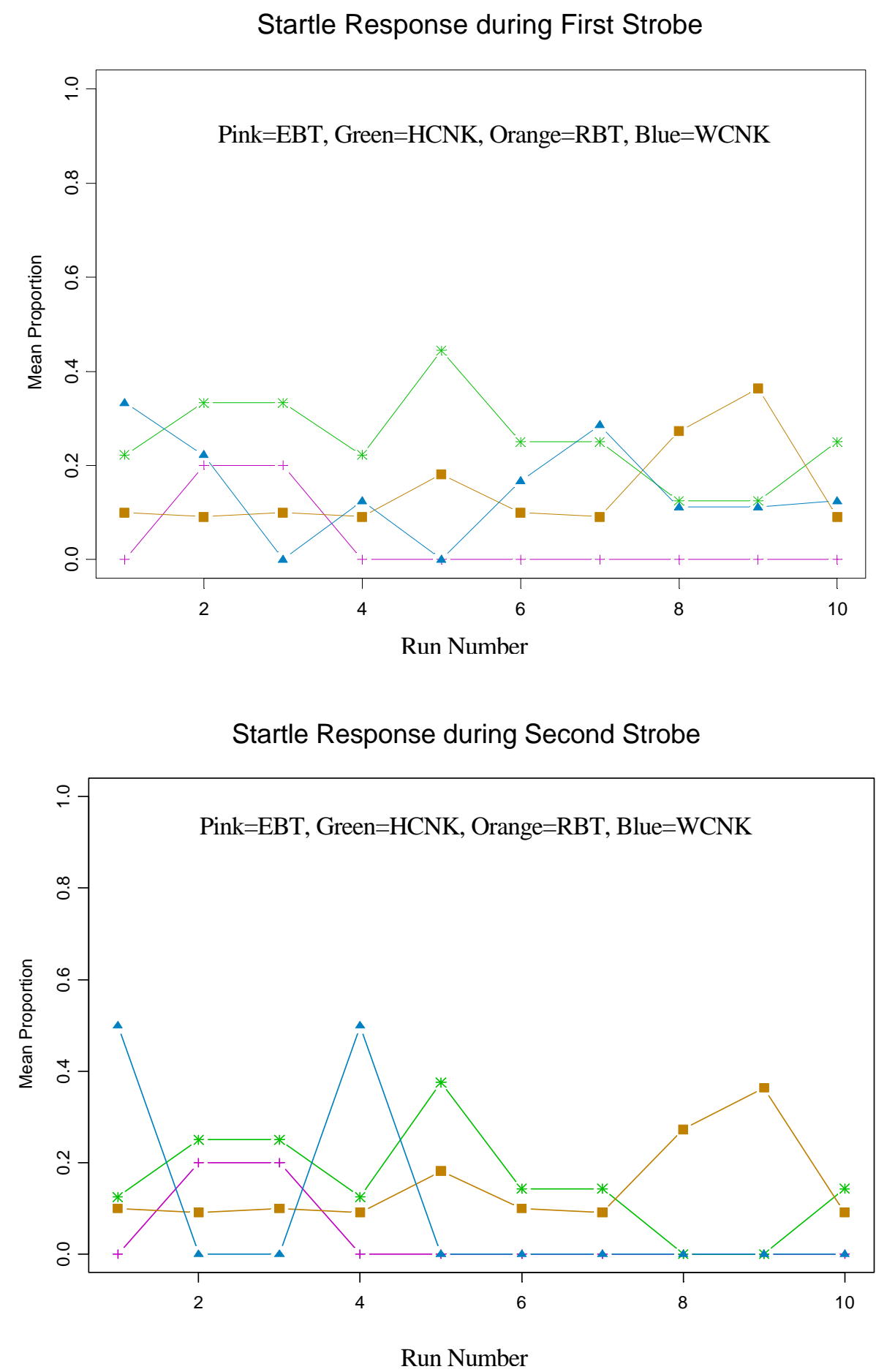

Figure 12. Each Plot Shows the Proportion of Tests That Showed Startle Response for Each Run (exposure) During the First and Second Strobe Light 


\section{Movement Vectors}

Control vectors were taken also during the strobe testing. Due to a limited amount of data only rainbow trout and wild chinook salmon vectors are plotted (Figure 13). The first eight strobe tests were with one strobe from the left of the pen $(x=0)$. The next 26 strobe light tests consisted of a first strobe followed by a second strobe (from the right). An example of the vector movements for rainbow trout and wild chinook salmon with the strobe light originating from the left $(x=0)$ is characterized by a profound avoidance pattern generally down and away from the light source (Figure 14).
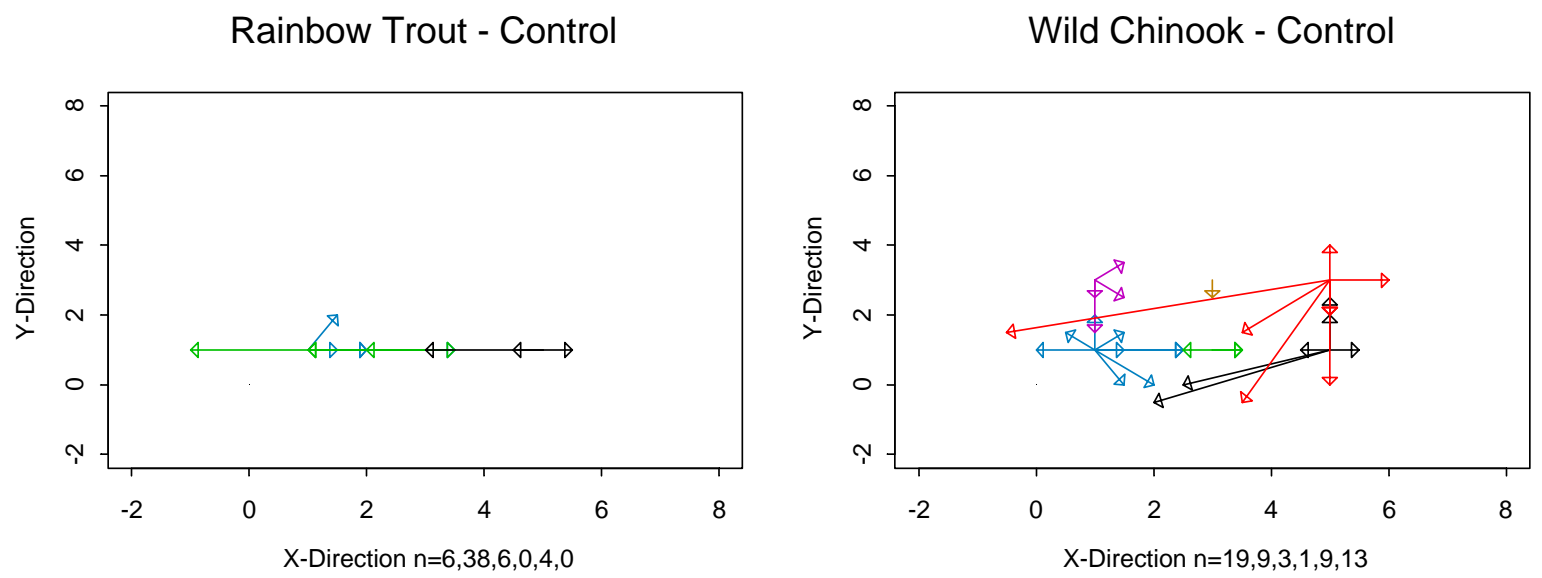

Figure 13. Movement Vector Plots During the Control Period for RBT and WCNK. The sample sizes for the six centering locations are in the $\mathrm{X}$-axis label for each plot.

Rainbow Trout - First Strobe (strobe from front)

Wild Chinook - First Strobe (strobe from front)
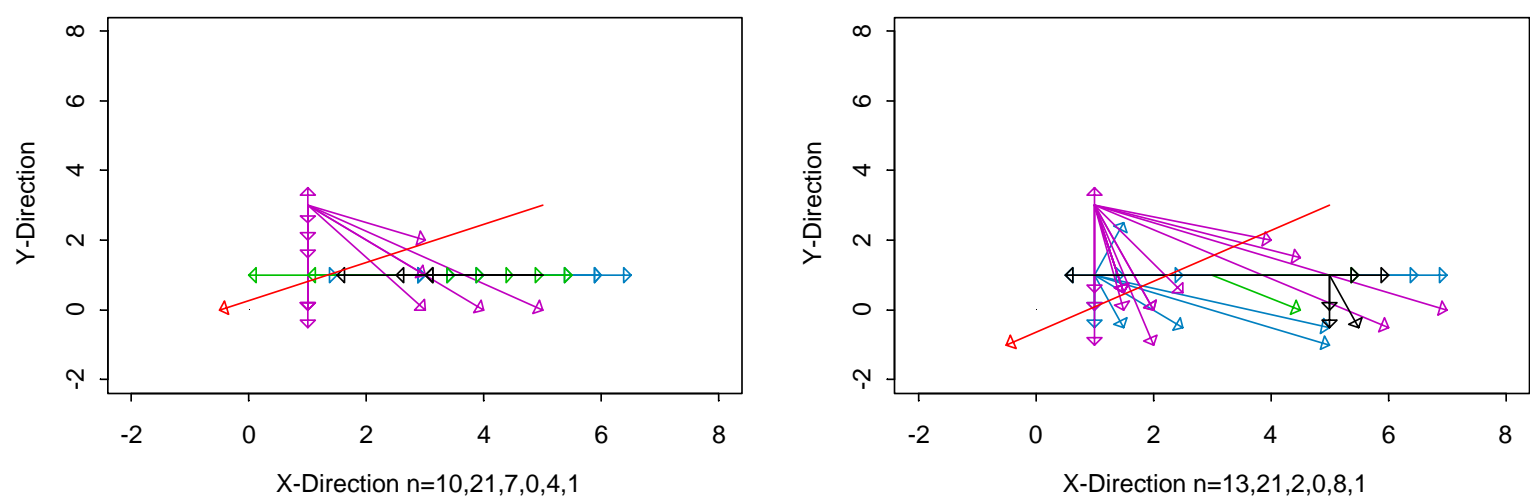

Figure 14. Movement Vector Plots During the First Strobe, When the Strobe was Coming From the Front or Left Side of Plots $(\mathrm{x}=0)$, for Each Species. The sample sizes for the six centering locations are in the $\mathrm{x}$-axis label for each plot. 


\section{Light Intensity Measurements}

Measurements of light intensity were taken to determine if the net pen was influencing the light intensity and to obtain ambient light filtering through the tarp. No difference was observed in light intensity when measurements were taken with and without the net pen in place using clear well water. An ambient light level of 10 lux was measured at the $0.5 \mathrm{~m}$ below the water surface with the gray tarp covering the tank. In an effort to determine light adsorption in a simulated turbid water environment, silt was added and mixed in the tank to obtain a water turbidity of ( 10 NTU's). Measurements were gathered from a signal strobe light, which was placed $1 \mathrm{~m}$ below the water surface without the tarp covering the tank. The photometer was positioned on axis with the strobe light and moved away at 0.5$\mathrm{m}$ intervals to a maximum range of $3.1 \mathrm{~m}$. Results from these measurements show a steady decay rate under the turbid water condition and a relatively constant level of over 100-lux out to $2.1 \mathrm{~m}$, then falling to 50 lux in clear water (Figure 15).

Strobe Light Measurement (Clear Water)

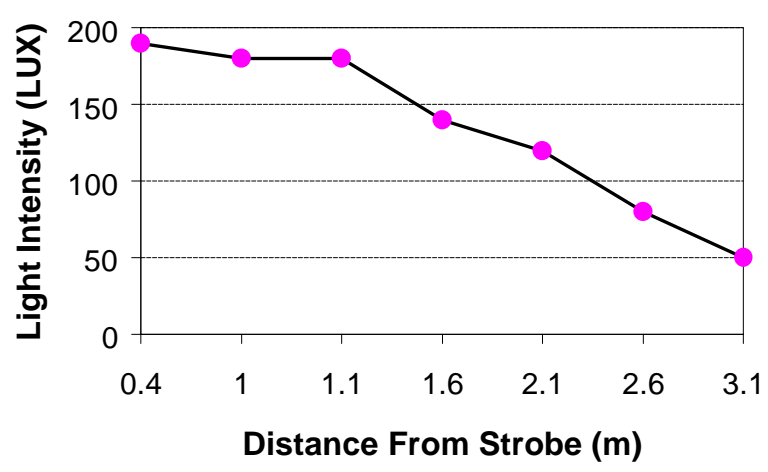

Strobe Light Measurement (10 NTU's)

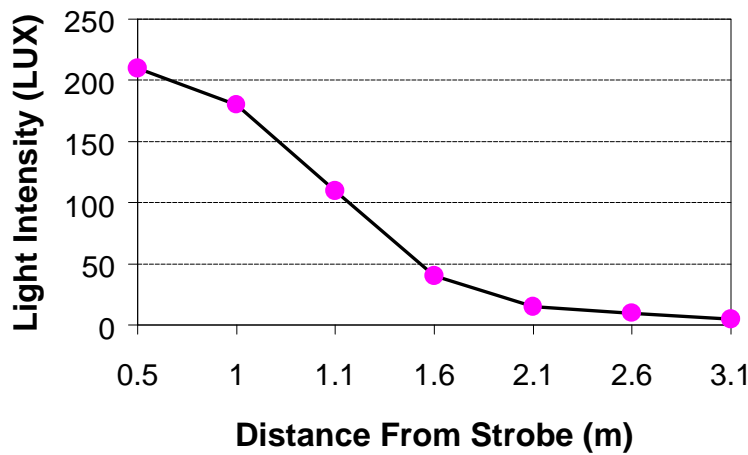

Figure 15. Light Intensity Measurements Illustrating Strobe Light Adsorption in Clear Well Water and Turbid Water (flashrate $=300 \mathrm{fpm})$ 


\section{Discussion}

In order to make valid conclusions about these experiments, a basic understanding of how juvenile fish perceive the stimulus used is helpful. Our findings demonstrated that behavior patterns differ when chinook salmon and char fry are subjected to infrasound and strobe lights in a laboratory setting. These behaviors are complex and often difficult to evaluate even under controlled laboratory experiments. Since test fish used in these tests were for the most part still developing their sensory perception of sound and light, their behavior responses to the subjected stimulus is apt to change as the fish matures (Fernald 1988; Popper 1993). The basic objective of this research was to determine if infrasound or strobe lights could be used in conjunction with screening facilities to deter or guide fish to safe passage routes. Because small fish are present and are the most susceptible to becoming impinged or passing though or around the screens, our tests were conducted using small (fry sized) salmonids and char). The likely deployment location for behavior barriers would be near the point of diversion to prevent entrainment or near the screen face to direct fish to the bypass (Figure 16). The effective range of the devices is also an important aspect if these devices can be used in conjunction with the screening facilities. Based on the particle acceleration values for the VDS used in our tests the effective range on axis is expected to be about $4 \mathrm{~m}$ in a controlled test tank (Carlson and Campana 1996). Studies using strobe lights have shown an effective range of $6 \mathrm{~m}$ for juvenile coho salmon under low ambient lighting (Ploskey and Johnson 1998, Ploskey et al. 1998). These ranges would be sufficient to prevent entrainment at most sites. Other factors such as water velocity, turbidity, and debris would need to be considered.

Based on the findings of these tests a number of conclusions can be stated about Infrasound and strobe lights and are discussed in the following paragraphs.

\section{Infrasound}

- Wild chinook salmon were most likely to respond in the near field with avoidance/startle behaviors followed by hatchery chinook salmon.

- Movement patterns were generally down and away from the VDS during initial exposures.

- Chinook salmon become easily habituated to repeated exposures during short-term testing, which suggest that the interval of exposure was too short to acquire consistent responses.

- Prolonging the acclimation period from 3-15 $\mathrm{h}$ reduced the initial avoidance responses for wild and hatchery chinook salmon.

- Infrasound elicited little if any response in rainbow trout and eastern brook trout.

While infrasound elicited avoidance responses for chinook salmon during the initial exposures the rate at which the tests groups habituated may not be as important. The rational for this is that emigrating salmonids would be expected to have a relatively long interval between encountering a series of 


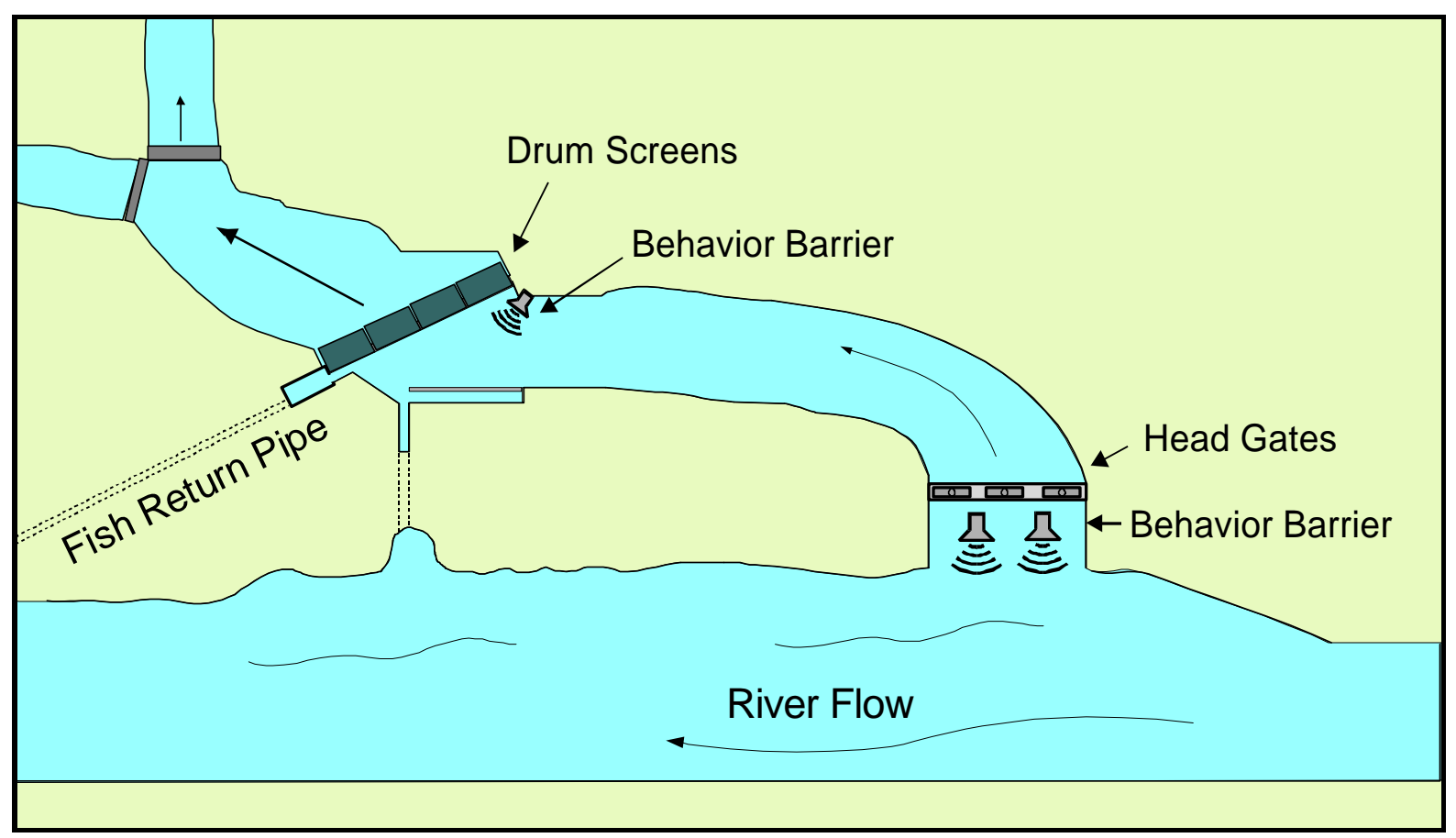

Figure 16. Generic Irrigation Diversion Facility with Behavior Barrier Component

behavior barriers if these devices were to be implemented. The responses of wild and hatchery chinook, as well as rainbow trout fry, were not as profound as observations made during similar tests conducted in 1996 using the identical VDS (Mueller et al. 1998). The study concluded that infrasound was moderately successful at producing avoidance responses in wild and hatchery chinook salmon and rainbow trout fry $(25-40 \mathrm{~mm})$ in laboratory experiments. These tests were conducted with a limited number of replicates (4) and were not subjected to statistical analysis. Based on these lab studies wild chinook salmon fry would be the most susceptible to being deterred by infrasound in the near field. We designed the tests so that a comparison of fish responses to a short and long acclimation period could be determined. A natural assumption would be that the fish response to a perceived danger would be more profound if fish were acclimated to new environment for an extended period. Our findings indicate that fish response was more profound for short acclimation periods at least for chinook salmon. Relating this result as to what may occur at a diversion is important because the acclimation period of emigrating salmonids would be expected to be short when fish encounter a diversion or screen.

Other studies have demonstrated that high particle acceleration infrasound was effective at producing startle and avoidance responses using hatchery reared chinook salmon, Atlantic salmon, and brown trout Knudsen et al. (1992, 1994, and 1997). Test fish used in these studies ranged in size from 100-150 mm. More recent field studies concluded that infrasound devices were mildly effective at deterring migrating and caged juvenile salmon smolts (Amaral et al.1998; Ploskey et al. 1998). 


\section{Strobe Lights}

- Rainbow trout, wild and hatchery chinook salmon test groups exhibited consistent avoidance responses to the strobe light.

- Little if any habituation was observed during the repeated exposures.

- Startle responses while not as profound as the initial infrasound tests were more consistent.

- Eastern brook trout did not display any avoidance/startle responses to the strobe lights.

- Movement vectors were generally down and away from the most intensely illuminated areas of the net pen.

Our experiments suggest that under controlled laboratory experiments the use of strobe lights are effective at producing avoidance responses in wild and hatchery chinook and rainbow trout fry $(25-40 \mathrm{~mm})$ in contrast to eastern brook trout, which were least likely to be affected by strobe lights. These results demonstrate that even during the early stage of development the test species were able to discern sudden changes in light intensity and were repelled. Why no discernable behavior was noted for eastern brook trout may be explained by the fact that their spectral makeup may differ in respect to the number or development of cones in the eye. Studies to confirm this speculation have not been conducted with eastern brook trout. Research suggests that as the eye grows larger and the number of cones increase, the optics of the eye leads to improved resolution of an image (Northmore et al. 1978). It is also noted that the spectral response of the eye differs within the species and life stage of the fish (Fernald 1988).

Several laboratory studies have been conducted on juvenile salmonids on their reaction to strobe lights (Nemeth and Anderson 1992; Puckett and Anderson 1987 among others). The majority of the findings conclude a moderate to strong avoidance response in chinook salmon smolts to strobe and mercury lights. Researchers conducting field studies also have found that chinook salmon will avoid strobe light illuminated areas especially during nighttime or deepwater installations (Amaral et al. 1998; Ploskey et al 1998). The study also found migrating chinook juvenile salmonids are much more likely to respond to strobe lights when ambient light levels are low such as dusk or nighttime or when fish migrate to deeper water. Other studies have found juvenile chinook salmon will avoid strobe lights during daytime testing (Ploskey et al 1988; Nemeth and Anderson 1992).

The use of light as a deterrent would obviously be more effective in clear water environments. The majority of the migration of juvenile salmonids takes place during the spring freshet. During these periods tributaries often have a high silt load, which makes the water turbid. If strobe lights are to be implemented their effectiveness under turbid water conditions needs to be evaluated. Our measurements indicate that the light intensity measurements in turbid water (10 NTU's) remain comparable to clear water to a range of $1 \mathrm{~m}$. Intensity levels drop off to negligible levels beyond $1.5 \mathrm{~m}$. Studies by Anderson et al. (1988) found the effective range of strobe lights is dependant on environmental conditions (i.e., turbidity, time of day) and age and physical condition of the fish. 
A primary goal of this research was to determine what specific behaviors could be elicited from juvenile salmonids using infrasound and strobe lights in a laboratory setting so that a basis can be established for how these systems may perform in the field. We conclude that under clear water, low ambient light conditions, strobe lights appear to be more effective at eliciting more consistent avoidance responses for all species tested with the exception of eastern brook trout, which had little or no reaction to infrasound or strobe lights. In the near term, the commercial availability and results from current research make the use of strobe lights a practical compliment to physical barriers (i.e., fish screening facilities). 


\section{References}

Amaral, S.V., F.C. Winchell, B.J. McMahon, and E.P. Taft. 1998. Evaluation of Behavioral Guidance Technologies for Diverting Chinook Salmon Smolts at the Roza Dam Screening Facility. Prepared for the Yakima/Klickitat Fisheries Project, by Alden Research Laboratory Inc. Holden, MA.

Anderson, J.J., K.J. Puckett, and R.S. Nemeth. 1988. Studies on the Effect of Behavior on Fish Guidance Efficiency at Rocky Reach Dam: Avoidance to Strobe Light and Other Stimuli. FRIUW-8801, Fisheries Research Institute, University of Washington, Seattle, WA.

Carlson T.J, and R.D. Campana. 1996. Evaluation of the characteristics of a volume displacement infrasound source as a means for implementing a behavioral barrier to reduce movement of juvenile salmonids through the causeway separating the inner and outer portions of the Burbank Slough. Prepared for the U.S. Department of the Interior, Pacific Northwest Division, Boise, Idaho.

Carlson, T.J., and A.N. Popper. 1997. Using Sound to Modify Fish Behavior at PowerProduction and Water-Control Facilities: A Workshop. U.S. Department of Energy, Project 91029. Bonneville Power Administration, Portland, OR. 92-0710-01.

Fernald, R.D. 1988. "Aquatic Adaptations in Fish Eyes." In Sensory Biology of Aquatic Animals, eds. J. Atema, R.R. Fay, A.N. Popper, and W.N. Tavolga, , pp. 435-466. Springer-Verlag, NY.

Karlsen, H.E. 1992. "The Inner Ear is Responsible for Detection of Infrasound in the Perch" (perca fluviatilis).” Journal of Experimental Biology 171:163-172.

Knudsen, F.R., PS Enger, and O Sand. 1992. "Awareness Reactions and Avoidance Responses to Sound in Juvenile Atlantic Salmon, Salmo salar L.” Journal of Fish Biology 40:523-534.

Knudsen, F.R., P.S Enger, and O. Sand. 1994. "Avoidance Responses to Low Frequency Sound in Downstream Migrating Atlantic Salmon Smolt, Salmo salar L.” Journal of Fish Biology 45:227233.

Knudsen, F.R., C. B. Schreck, S. M. Knapp, P.S. Enger, and O. Sand. 1997. "Infrasound Produces Flight and Avoidance Responses in Pacific Juvenile Salmonids". Journal of Fish Biology. 51, 824-829.

Mueller, R.P., C.S. Abernethy, and D.A. Neitzel. 1995. A Fisheries Evaluation of the Dryden Fish Screening Facility. DOE/BP-00029-2, prepared by Pacific Northwest National Laboratory for the Bonneville Power Administration, Portland, OR. 
Mueller, R.P., D.A. Neitzel, W.V. Mavros, and T.J. Carlson. 1998. Evaluation of Low and High Frequency Sound for Enhancing Fish Screening Facilities to Protect Outmigrating Salmonids., prepared by Pacific Northwest National Laboratory for the U.S. Department of Energy, Bonneville Power Administration, Portland, OR.

Neitzel, D.A., C.S. Abernethy, and E.W. Lusty. 1990a. A Fisheries Evaluation of the Wapato, Sunnyside, and Toppenish Creek Canal Fish Screening Facilities Spring 1988. DOE/BP-01830-6, prepared by Pacific Northwest National Laboratory for the Bonneville Power Administration, Portland, OR.

Neitzel, D.A., C.S. Abernethy, and G.A. Martenson. 1990b. A Fisheries Evaluation of the Westside Ditch and Town Canal Fish Screening Facilities Spring 1990. DOE/BP-01830-9, prepared by Pacific Northwest National Laboratory for the Bonneville Power Administration, Portland, OR.

Nemeth, R.S., and J.J. Anderson. 1992. "Response of Juvenile Coho and Chinook Salmon to Strobe and Mercury Vapor Lights." American Journal of Fisheries Management 12:684-692.

Northwest Power Planning Council (NPPC). 1984. Columbia River Basin Fish and Wildlife Program: Measure 704(d). Portland, OR.

Northwest Power Planning Council (NPPC). 1987. Columbia River Basin Fish and Wildlife Program: Measure 1403.4. Portland, OR.

Northwest Power Planning Council (NPPC). 1994. Columbia River Basin Fish and Wildlife Program: Measure 7.10. Portland, OR.

Northmore, D.P.M., F.C. Volkmann, and D. Yager. 1978. "Vision in Fishes: Color and Pattern." In The Behavior of Fish and Other Aquatic Animals, ed. D. Mostofsky. Academic Press, NY.

Popper, A.N., and C. Platt. 1993. "Inner Ear and Lateral Line of Boney Fishes." In Evans, D.H. (ed.), The Physiology of Fishes, CRC Press, Inc., Boca Raton, FL.

Ploskey, G. R., and P.N. Johnson. 1998. Effectiveness of Strobe Lights for Eliciting Vertical Avoidance by Juvenile Salmon. U.S. Army Corps of Engineering, Waterways Experiment Station, Fisheries Engineering Team, Columbia River Basin, Portland, OR.

Ploskey, G. R., P.N. Johnson, M.G. Burczynski, J.M. Nestler, and T.J. Carlson. 1998. Effectiveness of Strobe Lights, Infrasound Devices, and a Sound Transducer for Eliciting Avoidance by Juvenile Salmonids. Technical Report of the U.S. Army Engineer District, Portland, OR.

Puckett, K.J. and J.J. Anderson. 1987. Behavioral Responses of Juvenile Salmonids to Strobe and Mercury Lights. FRI-UW-8717, Fisheries Research Institute, University of Washington, Seattle, WA. 
Sand, O., and H.E. Karlsen. 1986. “Detection of Infrasound by the Atlantic Cod.” Journal of Experimental Biology 125:197-204.

Sand, O., P.S. Enger, H.E. Karlsen. F. Knudsen, and T. Kvernstuen. 1999. Avoidance responses to infrasound in downstream migrating European silver eels, Anguilla anguilla. Env. Biol. Fish, In press. 